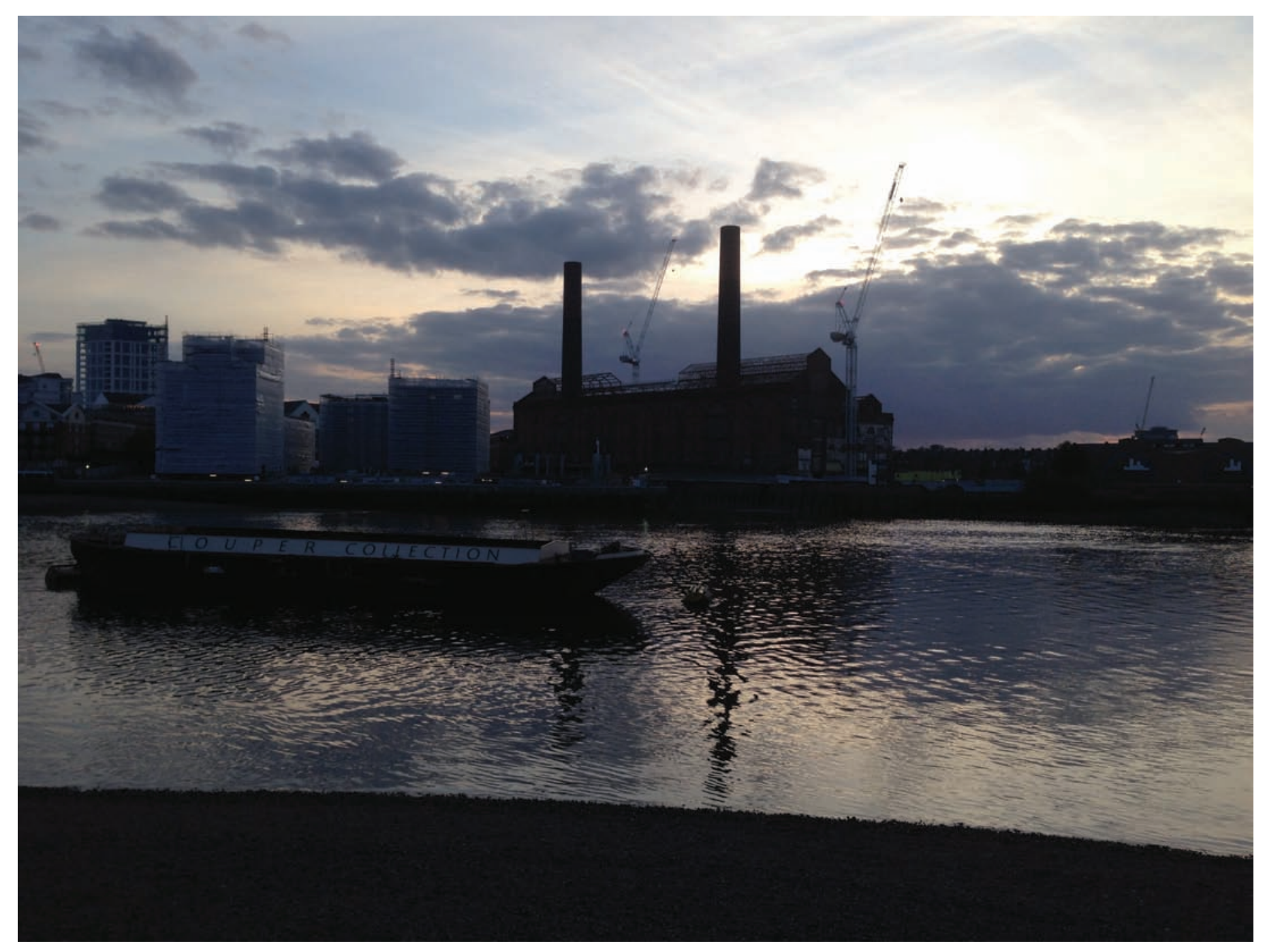

Figure 1: Architectural Forensics in Anonymous Monsters, ENIAtype, 2016. 


\section{Architectural Forensics in Anonymous Monsters}

Architectural forensics Anonymous monsters Augmented planning permission Digital forensics Reflexive architecture ENIAtype Architecture Construction Scaffolding
Abstract

Architecture is a crime if it does not involve environmental DNA and digital forensics to aid in the design of 4 the building. Architectural Forensics on Anonymous Monsters is a chthonic zenoarchaeology that constructs 5. new models of thinking through construction and physical construction with the earth. The anonymous mon- 6. ster could be the alternative contracting/constructing models and ideas that architects consider valuable and 7. inherently fundamental for architecture - the scaffolding of thought and the scaffolding of buildings. This scaf- 8 . folding could become the anonymous support structure that enables but also underpins the monster under 9. construction. This article is a design project developed to a highly tuned theoretical standpoint on how technol- 10 ogy alters consciousness for the individual and for society. With coined phrases such as 'reflexive architecture' 11. to explore the collapse of the biological and information divides whilst has re-applied the term syncretism to 12 explain our experience of multiple realities at once. Technology is a tool and a means for individuals to explore 13. pre-conceptions of themselves, to enter separate realities and bring back information. A computer can therefore be likened to undertaking a similar role to that of a shaman in accessing different levels of consciousness. Building as a constructed reality. 
ENIAtype research group is a state-of-the-art research group delving into the relationship between architecture, technology and philosophy across the University of Greenwich and the University of Kent. Our latest project investigated the impact of current digital modelling tools in producing complex architectural spatial environments at the Isle of Dogs in London.

We started the project with a two-week practical session within the Isle of Dogs, where the research group collected and documented architectural forensic models in three-dimensional virtual 10. and physical environments that were played back continuously on the environment under investiga-

10. tion. Consequentially, hybrid spaces were discovered and became tailored as evidence to support the 11. design of buildings to become architecture.

Architectural Forensic models encompass the seizure, forensic imaging (acquisition) and analysis of digital media through the production of a set of precise drawings and models. Forensics deals primarily with the recovery and analysis of latent evidence. Latent evidence can take many forms in your design ideas and drawings, which could be used to reshape the design of a building around new values and behaviours. This suggests that ecological design replacement towards ecological forensics could be accelerated by external shocks and shaped by the emergence of a new kind of environment 18. for a new kind of human being. Creating something more dynamic will at first abolish existing archi19. tectural models, almost unseen within the old system, but which will break through, reshaping the 20. built environment. This is possible because of three major changes design technology has brought 21. about in the use and application of digital tools in architecture, a shift away from representation and 22. towards documentation and the consequences of new spatial terrains yet to be explored.

Anonymous Monsters was developed three-dimensionally to aid in the design of tailored buildings in relation to its own complex architectural forensic evidence. An anonymous monster (aka the environment) is constructed by some unseen force directing spatial events, which are orchestrated by some unseen director. Architectural research queries to develop the programme of the building could be: How does gravity affect us? Where does weather come from? How much can we find out about you that you accidentally leave behind? Our only true relationship with the anonymous monsters is that it 29. is ubiquitous yet strangely anonymous in its complexity and architecture. We unpacked the guts of the 31. monster to generate an architectural framework that can have a dialogue with this unknown unknown.

31.

32.

\section{Design strategy}

34.

36. A design strategy was set up for the research group with the following leading questions: What is your bait? How can you attract the enemy's enemy? How will you attract the prey to your building? The 
ideas were to design a building as a weapon of the weak and the architecture has to continuously try 1. to achieve what the occupants want through an indirect route.

An initial focus was in marking out spaces by some invisible links between forensics, building and 3 . participant in their architectural forensic models, distancing the forensics from the environment - 4 . unfolding as a series of events in the environment as some form of design - manipulating the foren- 5 . sics towards some dramatic shifts in the design of the building, without any direct changes to the form 6 of the object. Forensic application after forensic application after forensic application - the architecture 7 . is an attempt to set a series of traps for the participant and occupant of the building. When we get 8 . entangled in this complex web of environmental forensics, can we cultivate it and engage with it? Find 9. who committed the crime? Through this greater understanding of how to design with this shifting 10 relationship, a revolution opens us up to a new understanding of the world - a strong temporal 11 dimension. It is up to each participant to discover what it is, as you don't design it, but you reveal its 12 relationships through the design of the architecture. You are complicit with it and re-orient yourself 13. with, through it and from it.

Using environmental applications the research group detected the full range of historical, environ- 15. mental and technological forensics to construct a four-dimensional virtual environment for people. 16. Buildings have often been seen as treating people as components in the machine. But there is another 17. way, whereby we treat buildings as complex components with a shifting relation with the environ- 18 ment and people over time.

Through our constantly shifting and dynamic relationship with buildings and the environment it 20. becomes clear that the manner in which our environmental DNA will be used against us in the future 21 . of buildings to become architecture is not known yet. Through the research group's architectural 22 forensic models, they individually identified and collated environmental, historical and technological 23 data to create time-based hinge architecture. A hinge architecture becomes an architecture under- 24 . stands that it is better to look for the processes that are ongoing and possibly unrecognized and manipulating them to create some sort of dramatic shift.

\section{Research projects}


1. and the environment as crime scenes. In the quest for objectivity, new methods of investigation were

2. developed merging environmental data with the design of spaces, calculations and material decisions.

3. Below is a range of speculative buildings developed as a series of networked shops and stores that

4. will trade with each other on parallel currencies. These buildings are dedicated to free time, networked

5. activities and free matter. The architecture considers different sets of associations between it and

6. human behaviour, in a whole range of different spatial relations, and encourages a change in percep-

7. tion about technology, ownership and work. The buildings will also focus on split-sites and develop a

8. complex response to the physical location through the development of an educational start-up prac-

9. tice. The split-sites will introduce two different programmes in one building to create elements of a

10. new system for a new way of living in the process of formation.

11.

12.

13.

14.

15. Shredding the post-war vortex is a microcosm that attempts to rebuild connections between the once 16. tight-knit communities of the Isle of Dogs during World War II.

17. The project explores the community from a forensic point of view, delving into memoirs and 18. accounts from residents during the Blitz and how this has a casual effect on the relationship between

19. the locals. The rise of Canary Wharf and luxury apartments on the Isle of Dogs has transformed the

20. once iconic docking industry. Research has shown that the unemployment rate among the youth on

21. the Isle of Dogs is at a high; therefore, having areas specifically for apprenticeship will help them gain

22. some qualification. Research has also shown that there is an ageing population and loneliness is at a

23. high. The architecture acts as a beacon of a reflexive architecture that retains the memories of the past

24. and projects them into the future. Memoirs manifest themselves into platforms that encourage the

25. community of all ages to engage with one another for the microcosm to flourish. Shredding the post-

26. war vortex engages the senses through tactile surfaces, social interaction, immersion and the elements

27. of earth, wind, water and fire. The architecture becomes a safe haven from the outside world where

28. nostalgia and childhood imagination can be explored. Participants work and play within the micro-

29. cosm, building relationships with their neighbours and piecing together fragmented memories of the

30. past while developing new memories themselves.

31.

32.

33. Mladen Varbanov, Invisible Networks and the New Observatory

34.

35. The New Observatory occupies a structure whose form is driven by the placement of architectural

36. elements from Canaletto's painting of Greenwich Naval College and Queen's House, with reference 


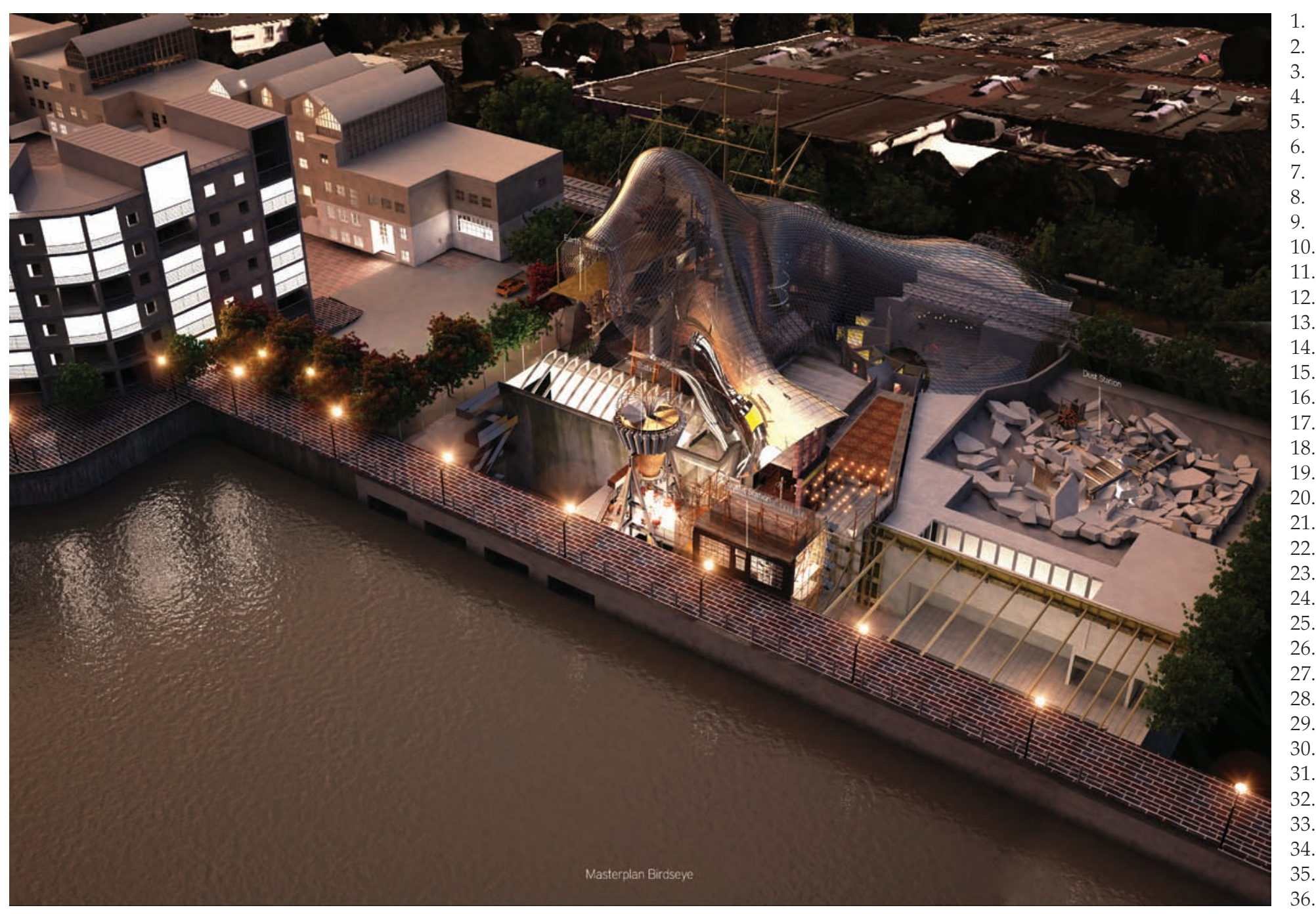




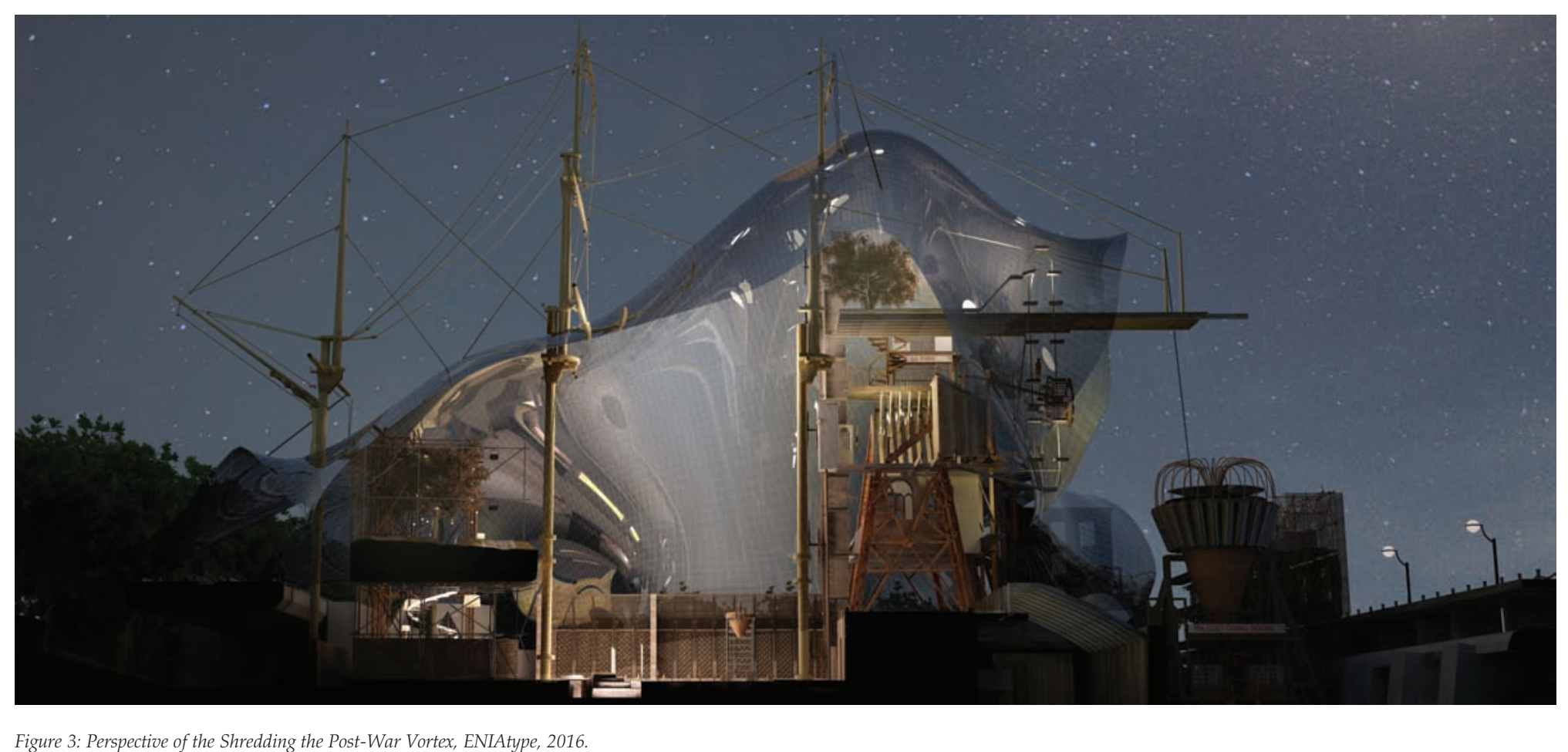

$\oplus$

Figure 3: Perspective of the Shredding the Post-War Vortex, ENIAtype, 2016. 
to his use of the camera obscura. The project gives architectural form to invisible phenomena that 1. occur around the site and its occupants, highlighting the role of the architect in generating conditions 2 . for new social ecologies. The New Observatory consists of three floors with different functions. The 3 . ground floor operates as a place where people could have a meal prepared from different types of 4 . insects. The first floor functions as an observatory for analysing the projected facades onto Mudchute 5. Farm and Park, with spaces to analyses invisible phenomena such as phone and Wi-Fi signals, wind 6 . speed direction, temperature and humidity. The different sensors located around the building will be 7 . collecting that data from the site, and through advanced computational algorithms it will be rendered 8 . onto the facade of the building under the form of different woven patterns.

\section{Koh Yuan Feng, Seeking Comfort in the Smokehouse}

$\begin{array}{ll}13 . & 12 .\end{array}$

Exploring human comfort and the extreme climate of a smokehouse stack with the exposed edge of 14 . the laminar wind flow at the Millwall Outer Dock. The project is a revisit into traditional hot and cold 15 . smoking techniques and enhancing the dining experience via the microclimate of hot and cold dining 16. vessels utilizing materials of varying U-values and its accompanying comfort food menu. The 17. program encompasses the use of the smokestack to smoke fish, meat and organic vegetables for the 18 . new market and restaurant. Located on soft marshy ground, and unobstructed strong westerly 19. winds, the light plays a crucial role in providing thermal comfort for the participant. Seeking Comfort 20 . in the Smokehouse aims to provide quality food with an architecture to enhance the Individual's 21. experience.

\section{Vince Choi, Time in Space Reassembling: The Chinese Kitchen in Ceramic Vessels}

The Chinese Kitchen in Ceramic Vessels is a project that experiments on the richness of spatial experience, time consumption and building materiality through investigating ways in which building properties can find their way into architectural forensics. The project is a response to a current issue in the Isle of Dogs with people preferring to buy 'food on the move' rather than enjoy 'food on the seat'. The reason - it takes a longer time to enjoy a proper meal and people need to get back to work. The architecture re-assembles the occupant's time consumption within varying spatial terrains. The architecture responds to the occupants by encouraging them to spend more time in highly detailed spaces and swiftly move through in highly tuned spaces. This is achieved through heating and cooling ceramics vessels embedded in the floors, walls and ceilings and the textures and materiality's of the spaces. Furthermore, "sihéyuàn"- 四合院, a historical type of residence was commonly found 


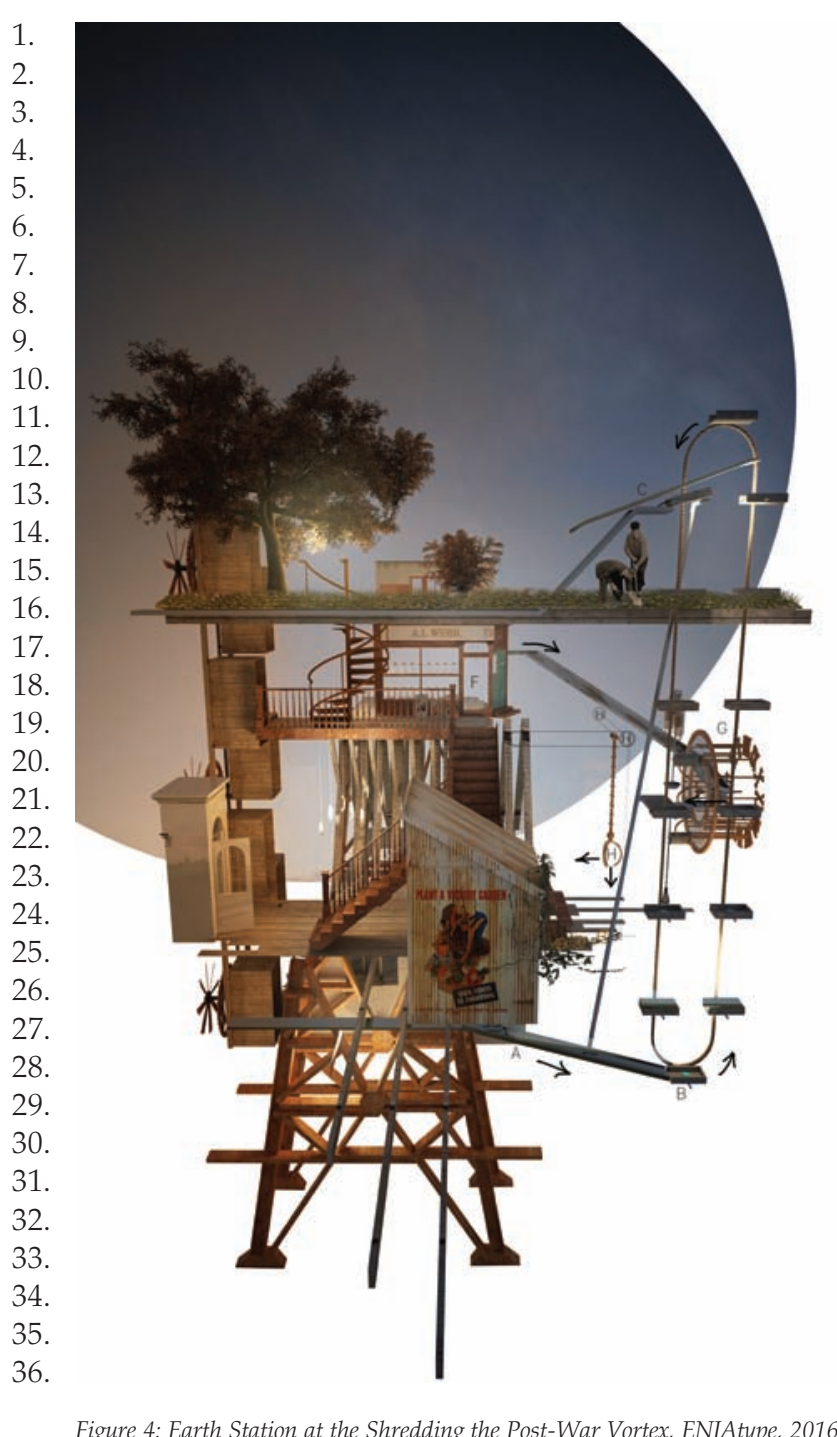




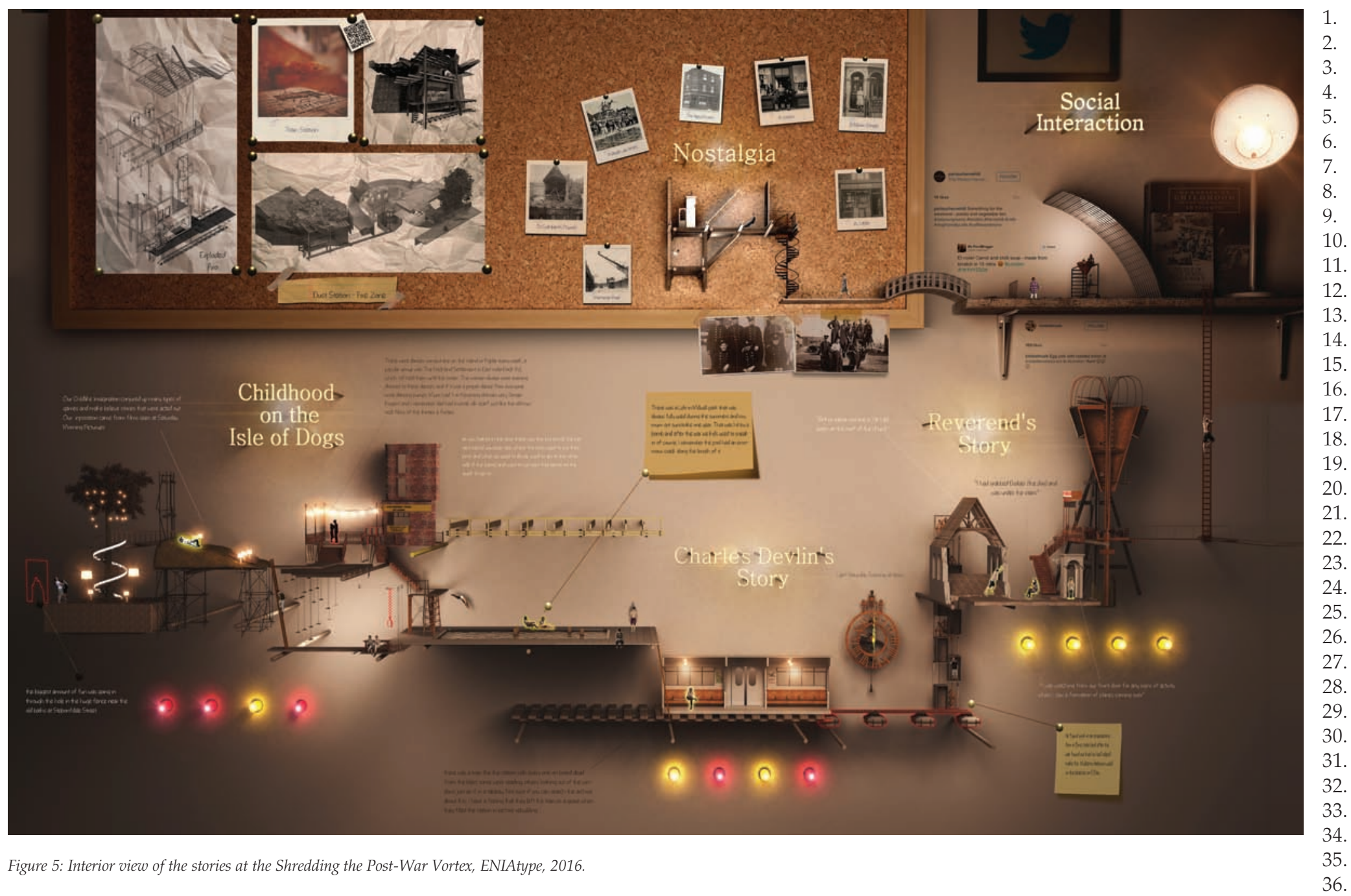




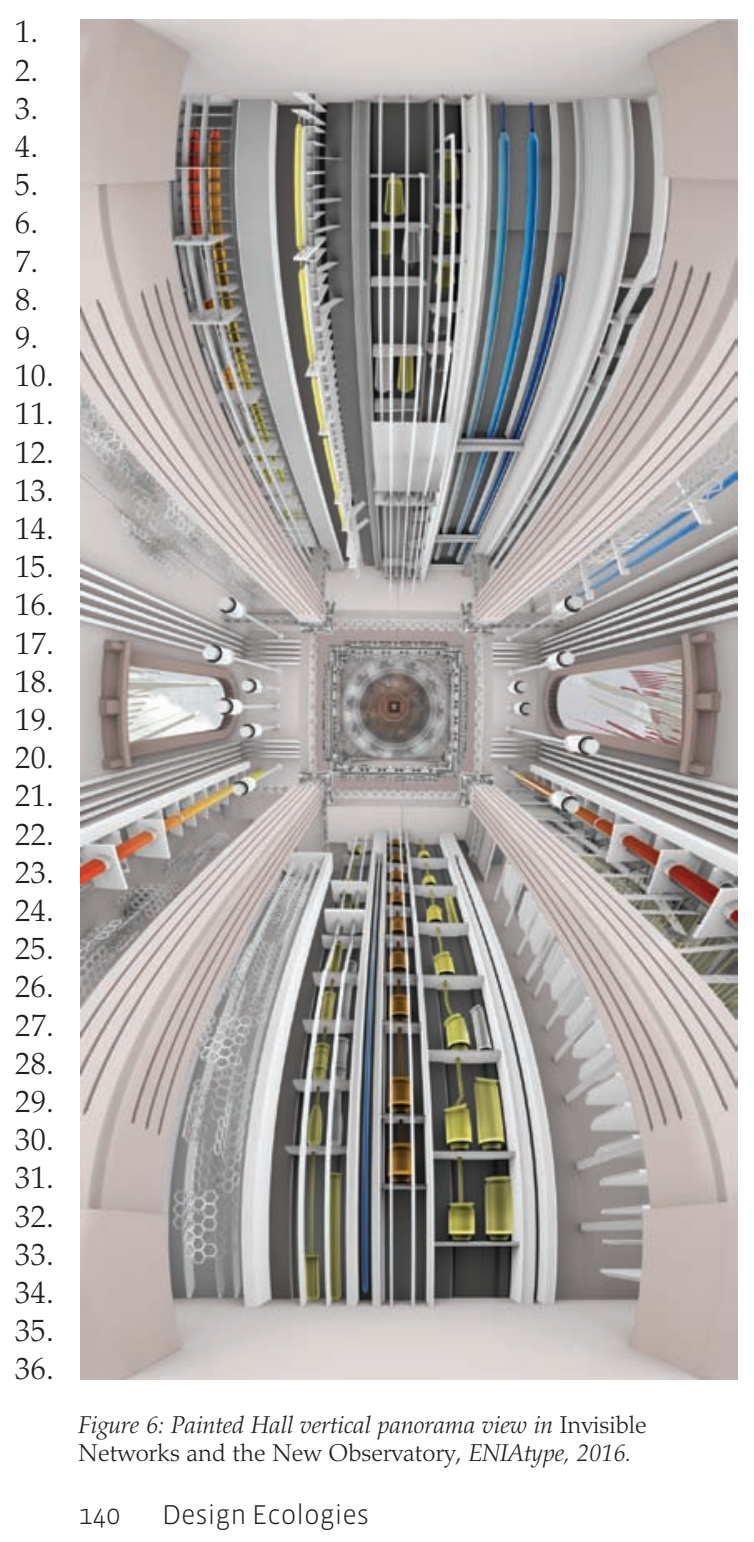

$\oplus$ 
throughout China, most famously in Beijing, it has applied into my space planning. The surfaces in 1. the building are manipulated as a mediator of the surrounding environment rather than a determi- 2 nant of the environment.

\section{Pravin Abraham, Resonations and Object Interference at the Recording Studios}

The project is about materials that resonate at differing frequencies with differing spatial environ- 8. ments for a series of recording studios. The building responds to sound from its surroundings by reso- 9. nating in it materially; new fractures and crumbling facades embrace this new spatial relationship. 10 Strategically orientated concrete walls with mechanical parabolic mirrors respond to the sound radiat- 11 ing through the sites location. These mirrors harvest sound from the area, which is then archived 12 through the recording studios. The sounds collected can then be integrated by participants using 13 specially designed recording facilities, with the aim of creating new and unique resonant sounds that 14 is directly influenced by the architecture of its space and surroundings. The building itself also collects 15 impact sound via the cacophony chamber, which contains a circulation path completely wrapped in 16 concrete. Microphones placed throughout the chamber then pick up these sounds. Essentially the 17 . chamber is an attempt at creating an architecture that acts as an instrument. The recording vessels, 18. where participants integrate the collected sound, are hung off the main building, so that they may 19. resonate with the main building as it receives vibrations from the site.

\section{Greta Lileikyte, Brunel's Pier and the Timber Dockyard}

In the south of the Isle of Dogs, the SS Great Eastern's launch ramp (1854), formed the basis of this project, which created a composition of workshops for construction of wooden boats, a bank for tree seeds and a pier for boats. The forensics that was discovered from the historical, solar, anemometric, bathymetric and geological data, guided the composition of the workshops, which raise knowledge and awareness about timber construction, and maintains the historical heritage. The site entails workshops for craft and wooden boat construction, a pier with a waiting area, café, ticket office, and an area for tree growth, which is monitored through the seed bank. The seeds and parts of the boat are produced through 3D printing using live cultures, however some Cross-Laminated Timber (CLT) is imported. There are three types of facades with the first layer that monitors the sun light and rotates accordingly to regulate a certain amount of light into the building, the second layer monitors the wind which regulates the ventilation inside of the building, and the third layer is a movable façade to provide privacy for the private jobs and the neighbouring residents. 


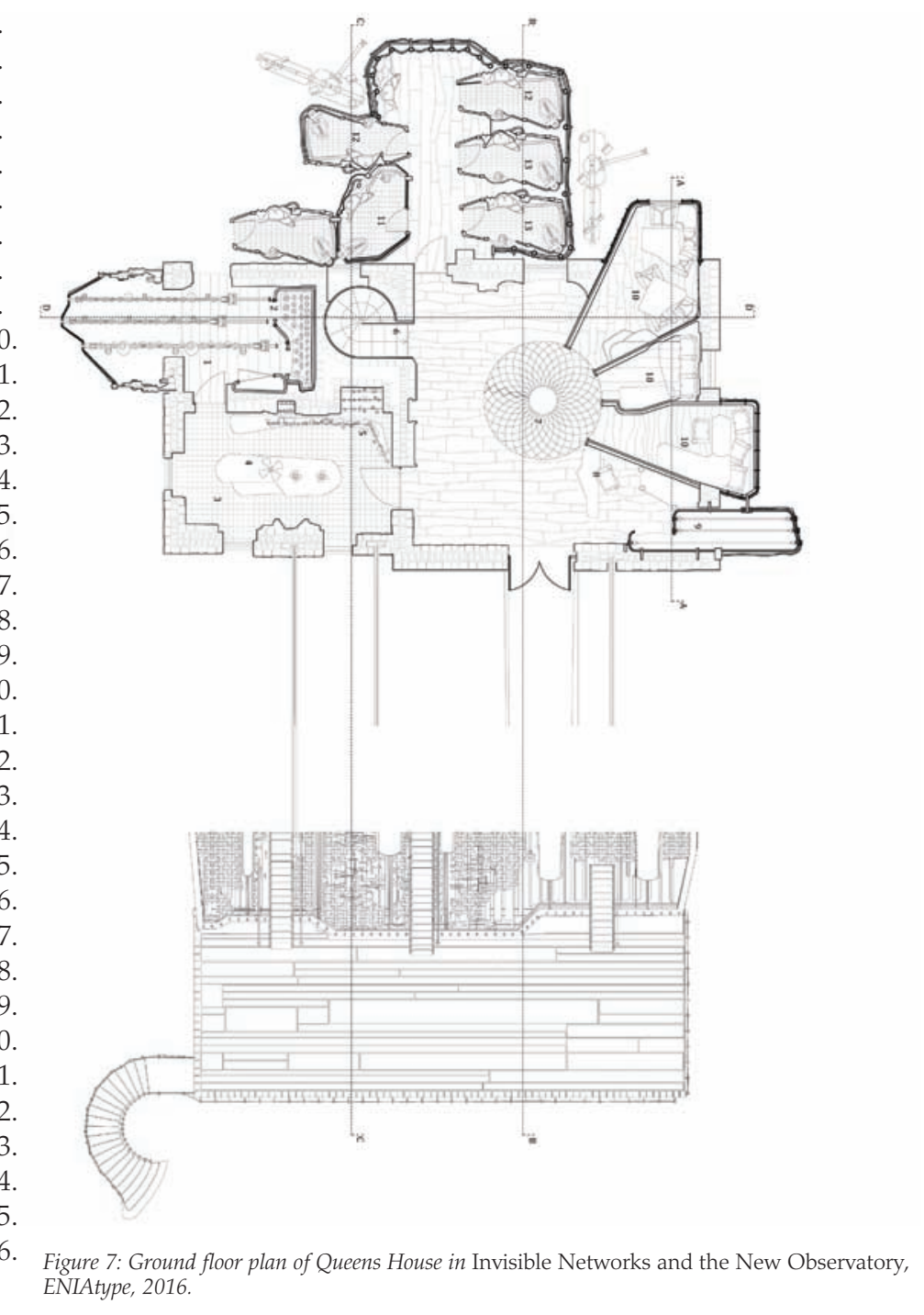




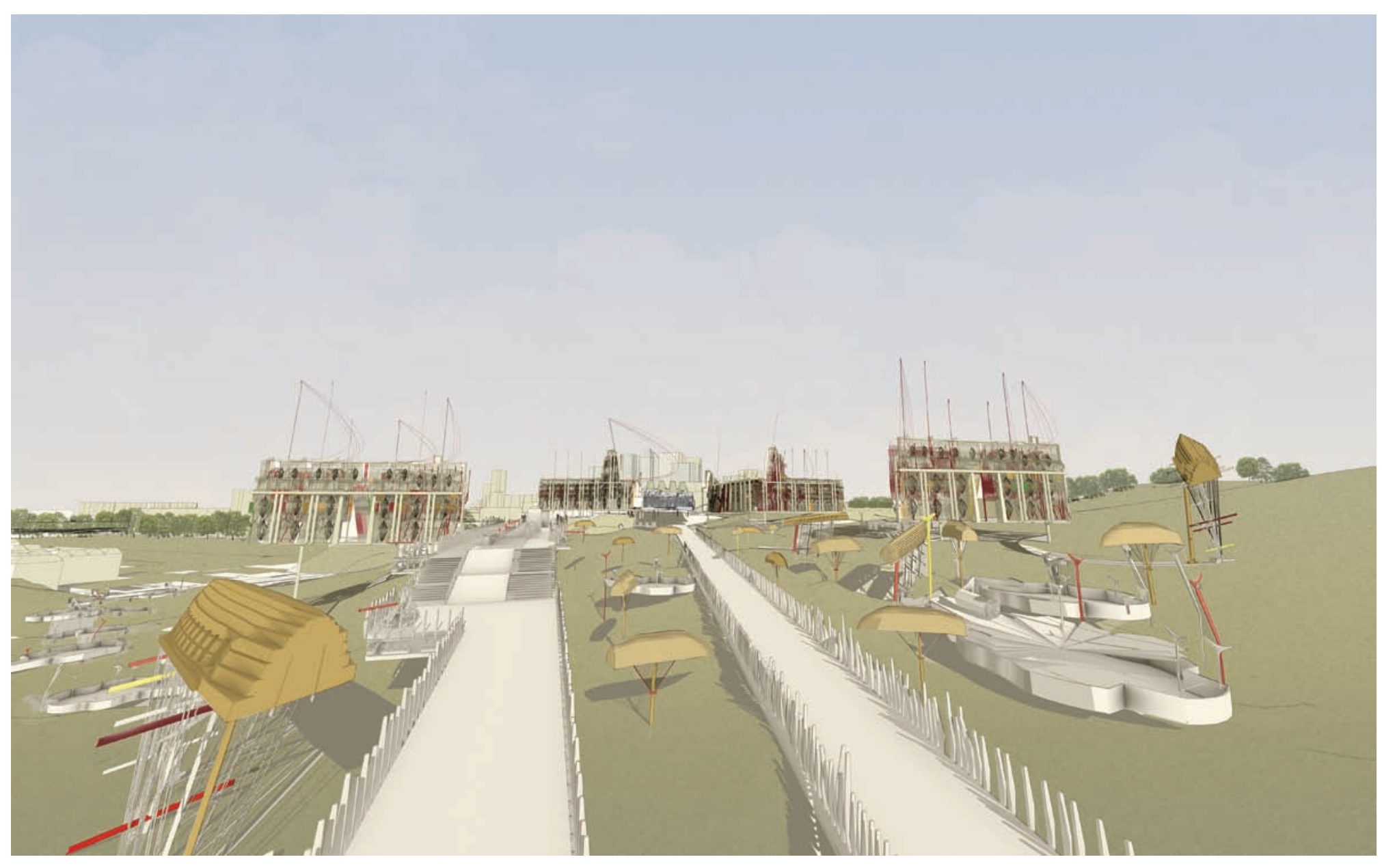




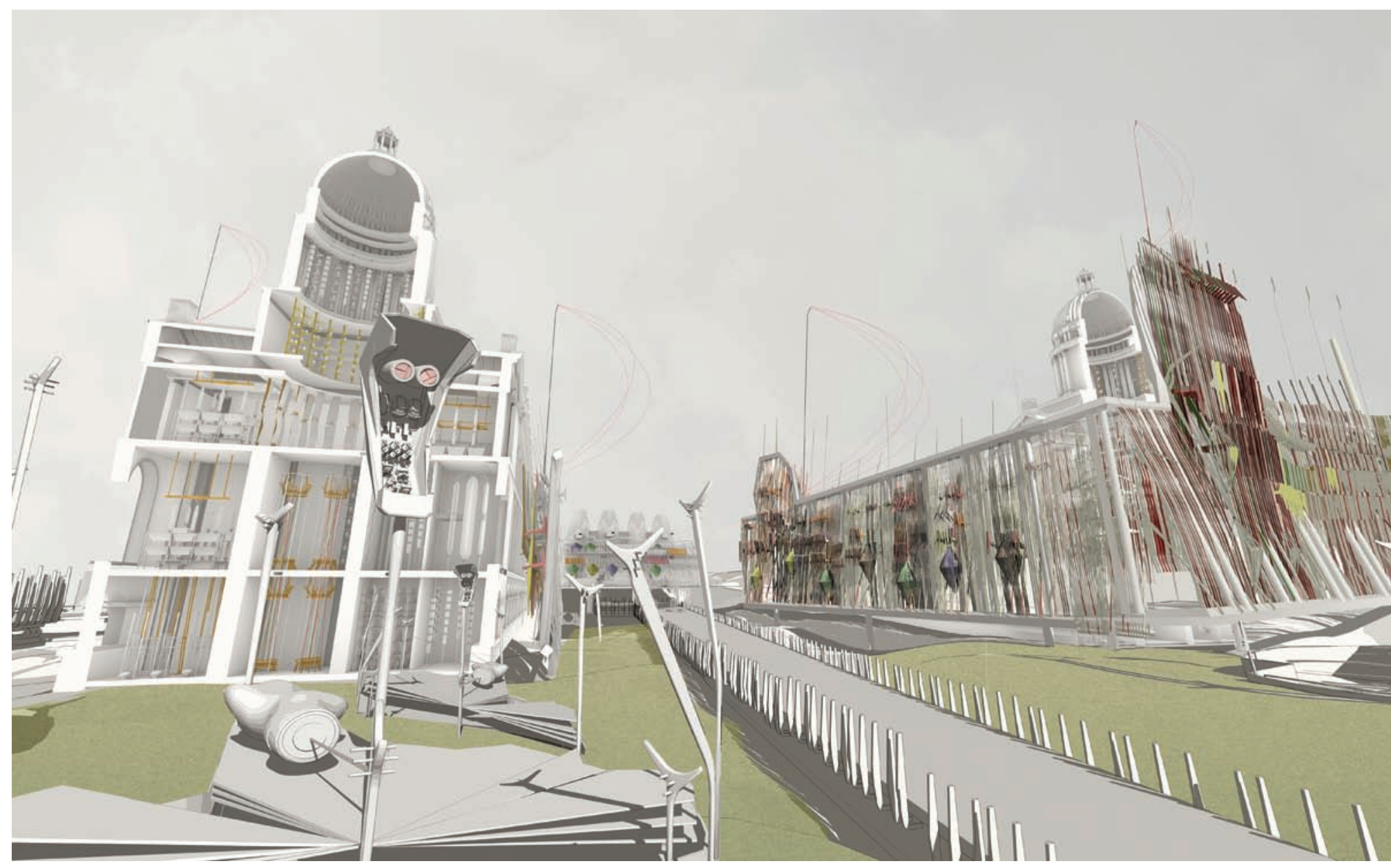

34. Figure 9: View of woven facades in the Painted Hall in Invisible Networks and the New Observatory, ENIAtype, 2016.

35.

36. 


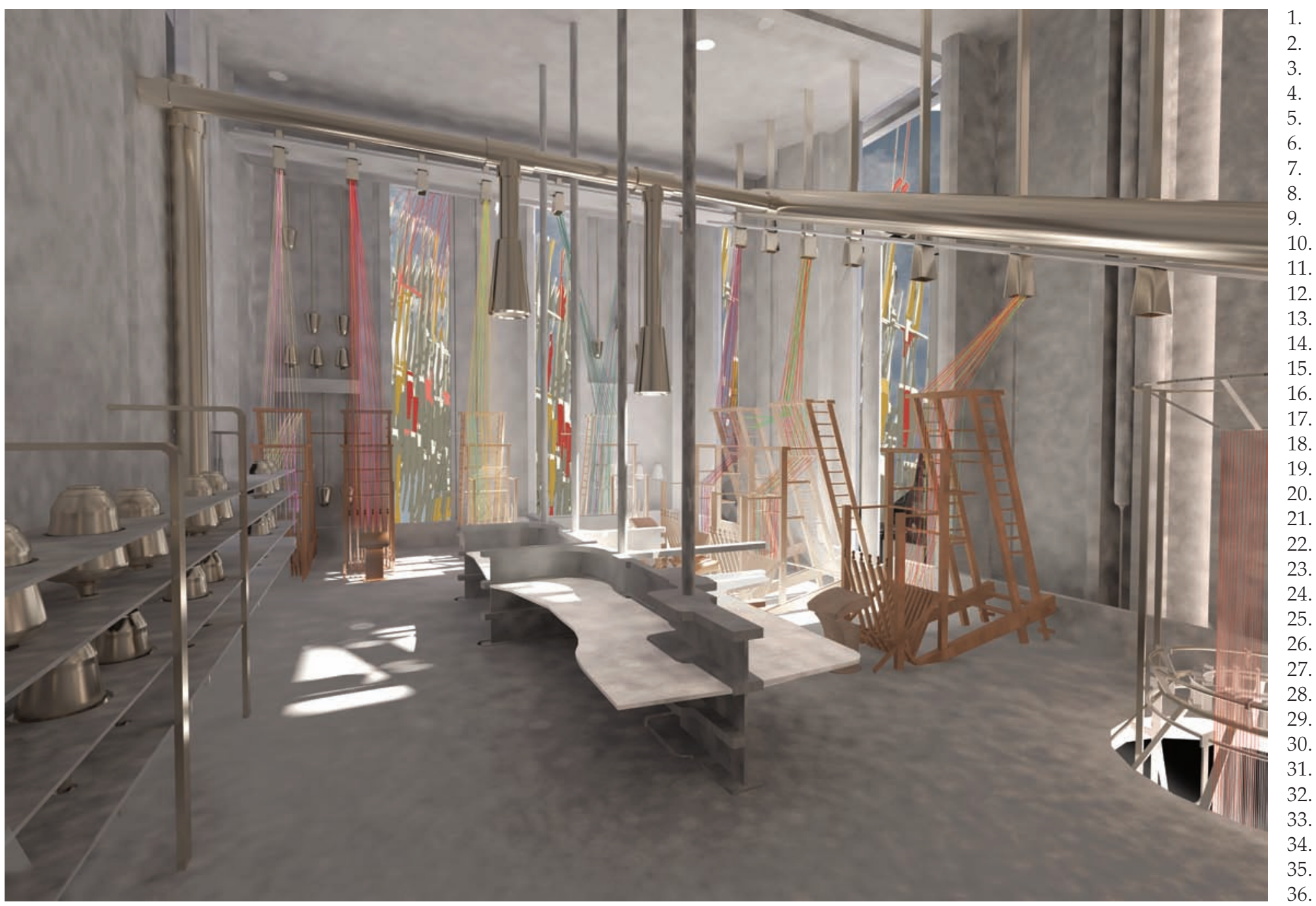

$\oplus$

Figure 10: Insect storage area in Invisible Networks and the New Observatory, ENIAtype, 2016. 


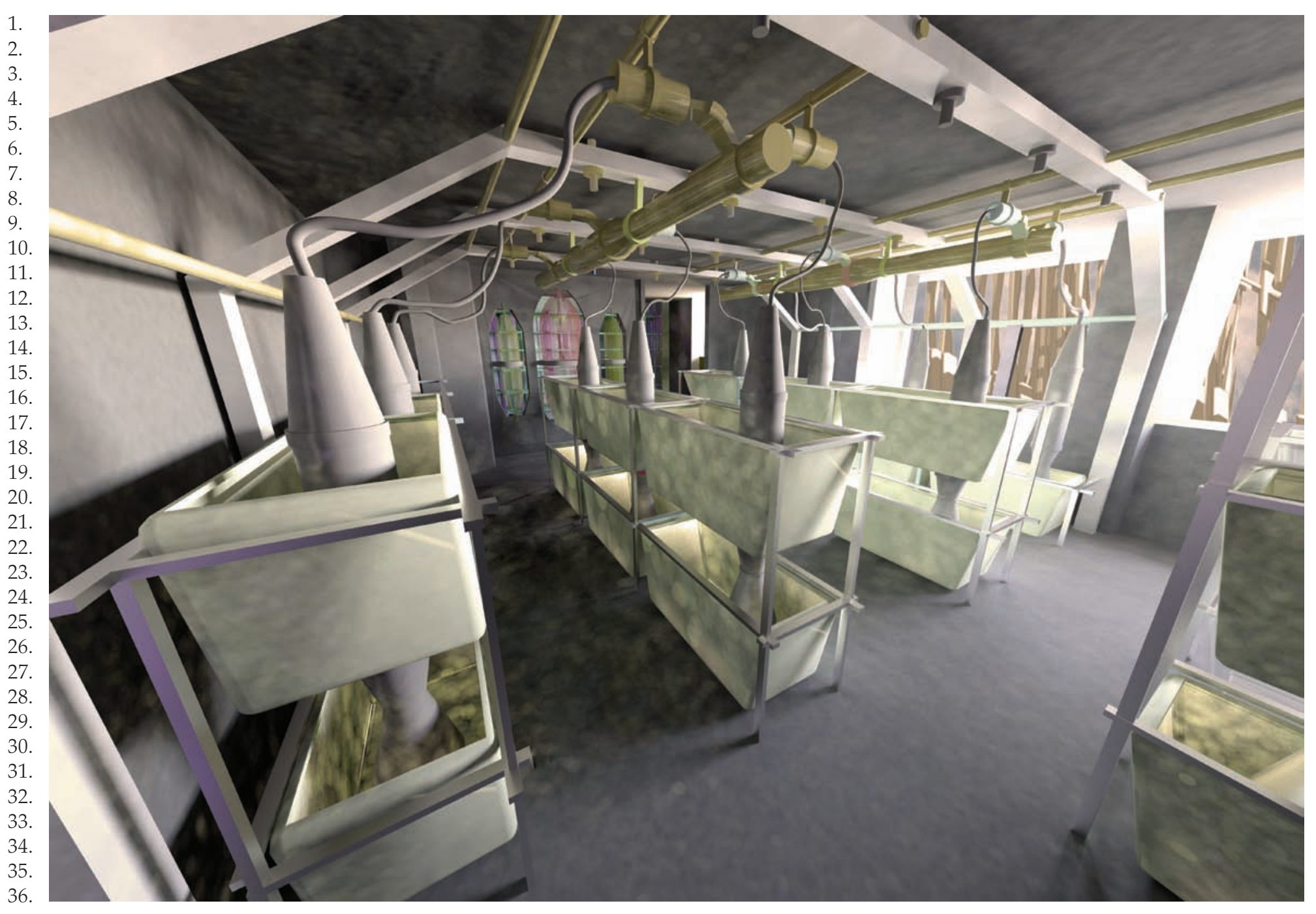

Figure 11: Workshop space in Invisible Networks and the New Observatory, ENIAtype, 2016.

146 Design Ecologies 


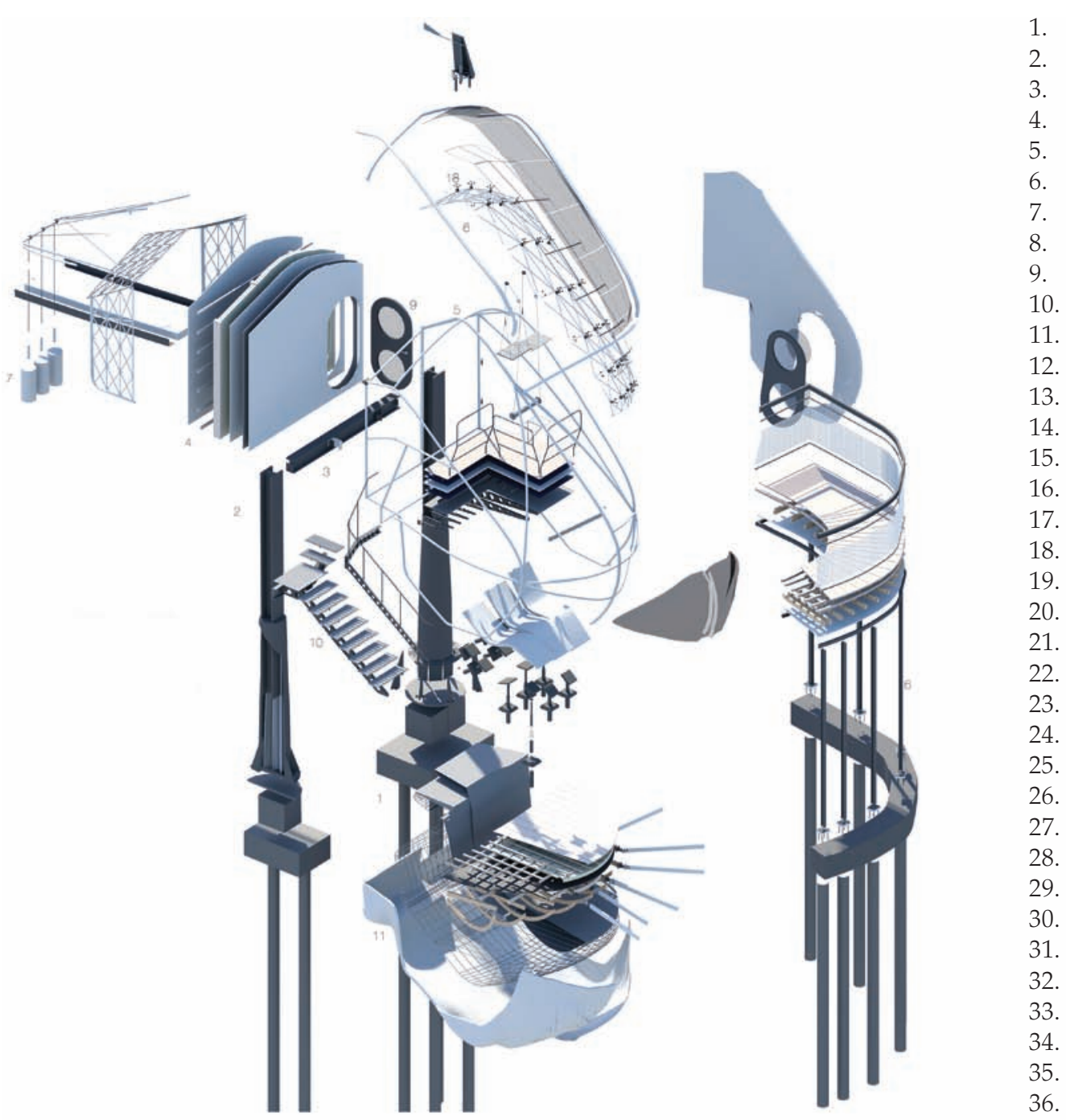

Figure 12: Constructional axonometric through the dining vessels in Seeking Comfort in the Smokehouse, ENIAtype, 2016. 
25.

26.

27.

28.

29.

30.

31.

32.

33.

34.

35.
36.

Figure 13: Section through the smokehouse kitchens and market area in Seeking Comfort in the Smokehouse, ENIAtype, 2016. 


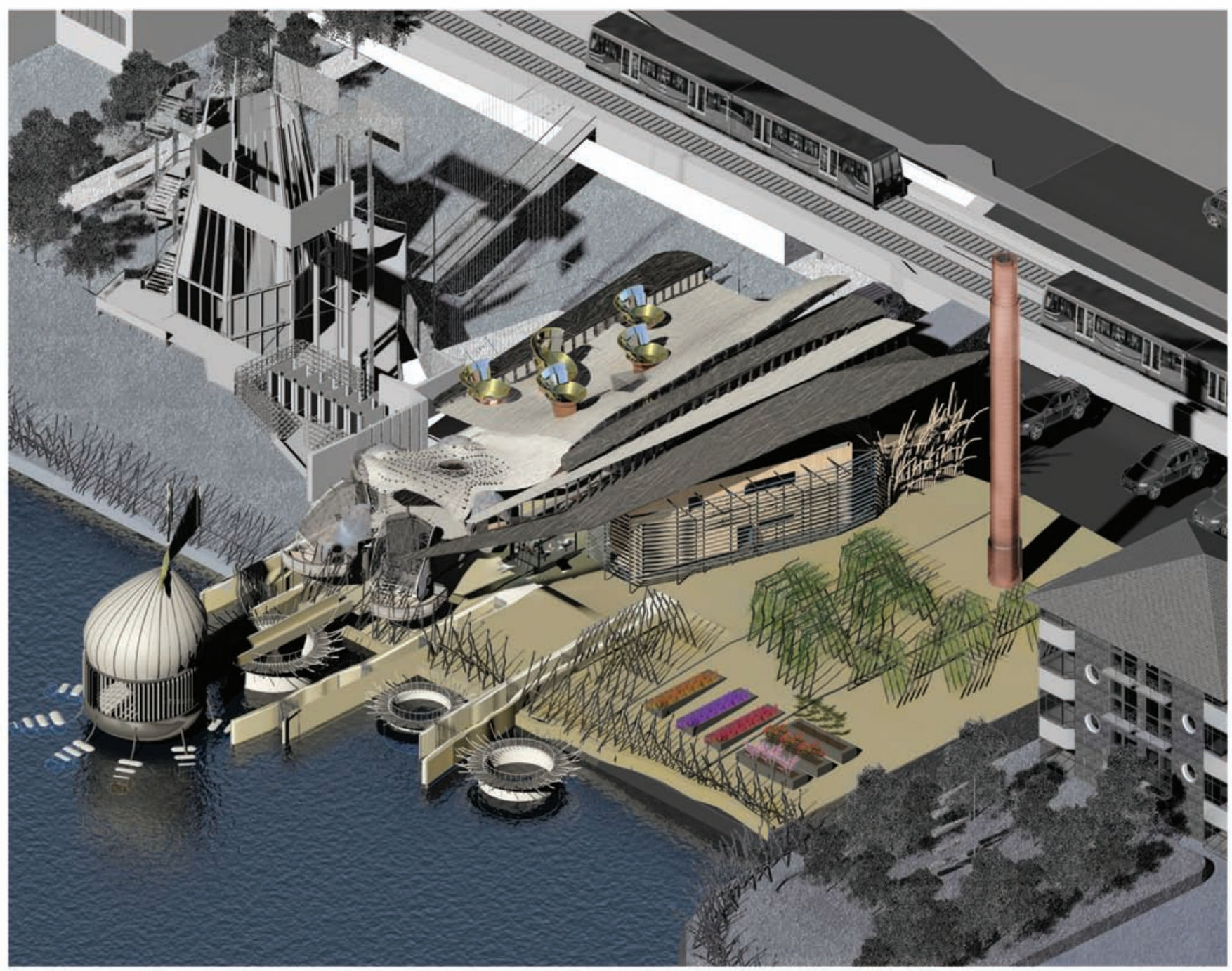


Construction Axonometric Drawing

Scale 1:50

Comfort in the Smokehouse

Steel Canopy Structure

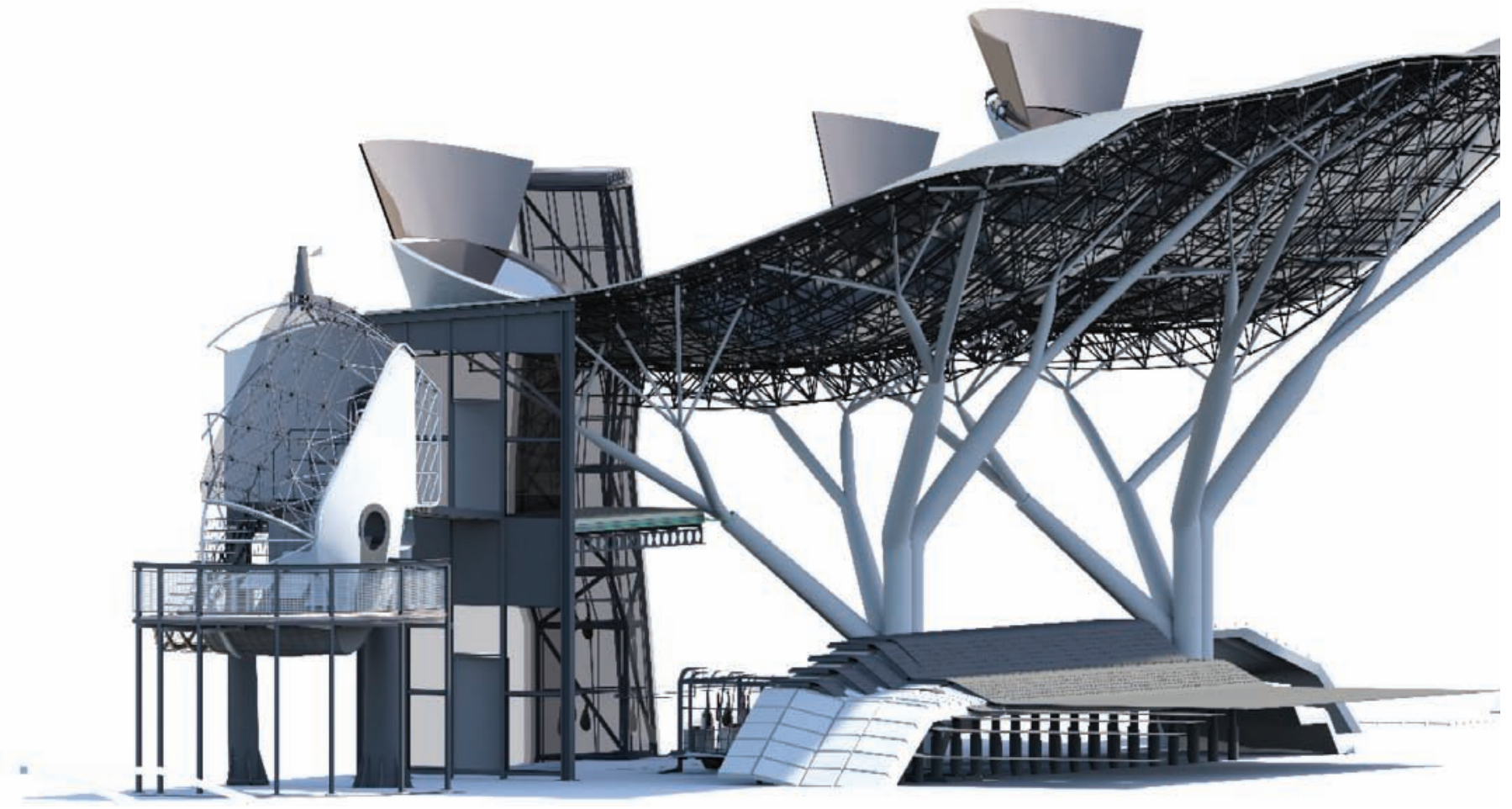

Figure 15: Perspective through the market area in Seeking Comfort in the Smokehouse, ENIAtype, 2016 


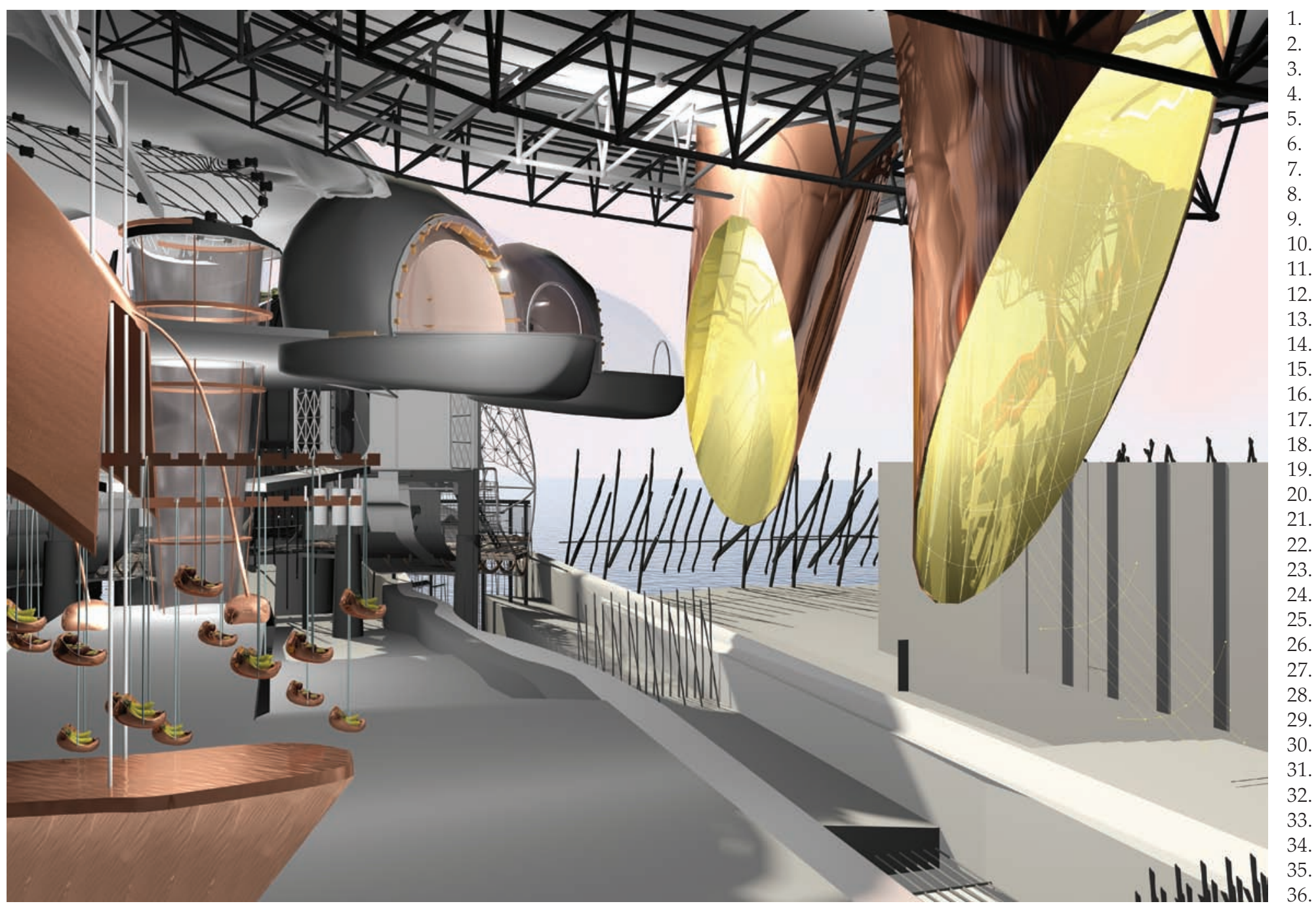

Figure 16: Perspective through the market area in Seeking Comfort in the Smokehouse, ENIAtype, 2016. 


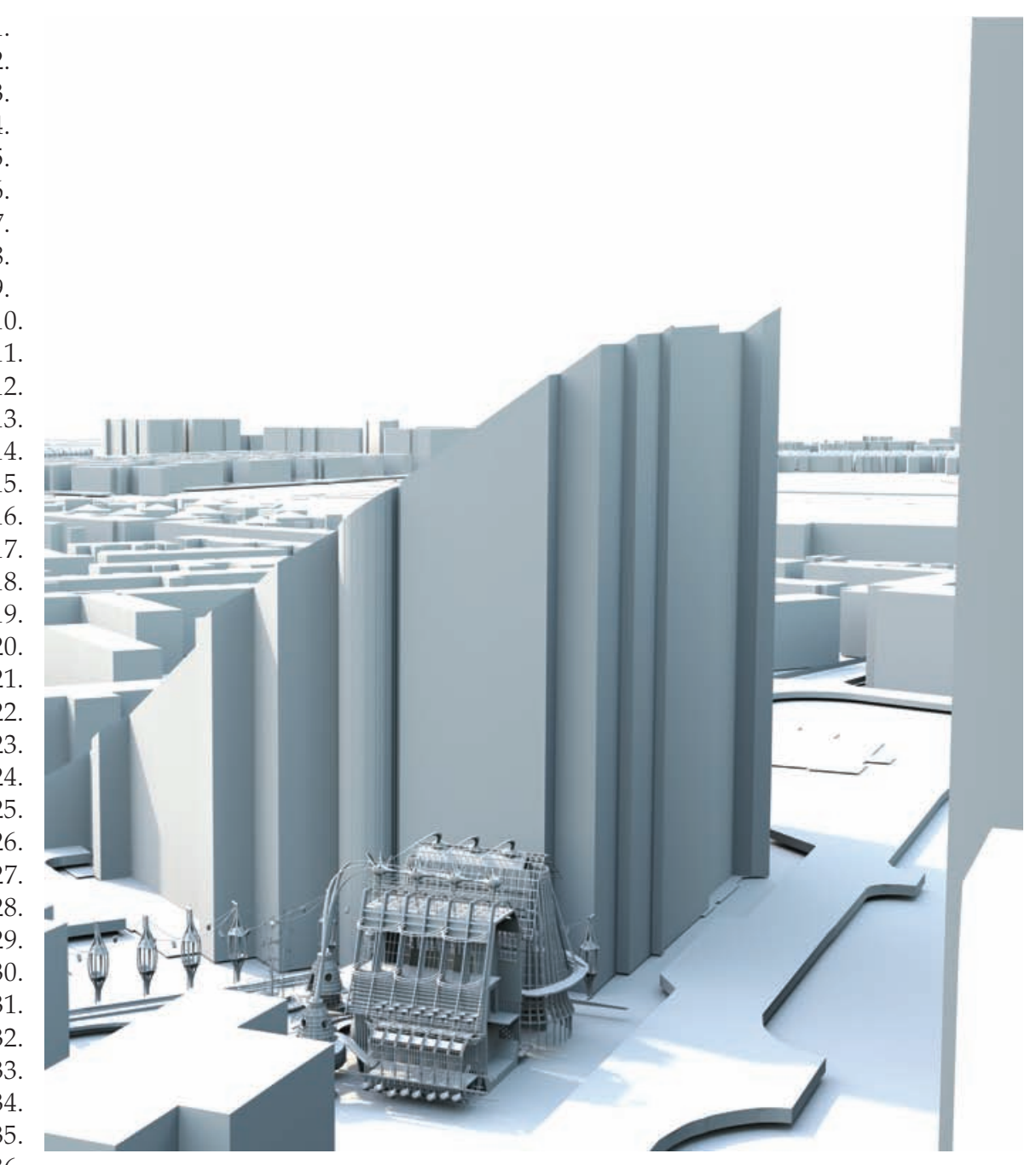

Figure 17: Aerial view of the Chinese Kitchen in Ceramic Vessels in Time in Space Reassembling: The Chinese Kitchen in Ceramic Vessels, ENIAtype, 2016. 


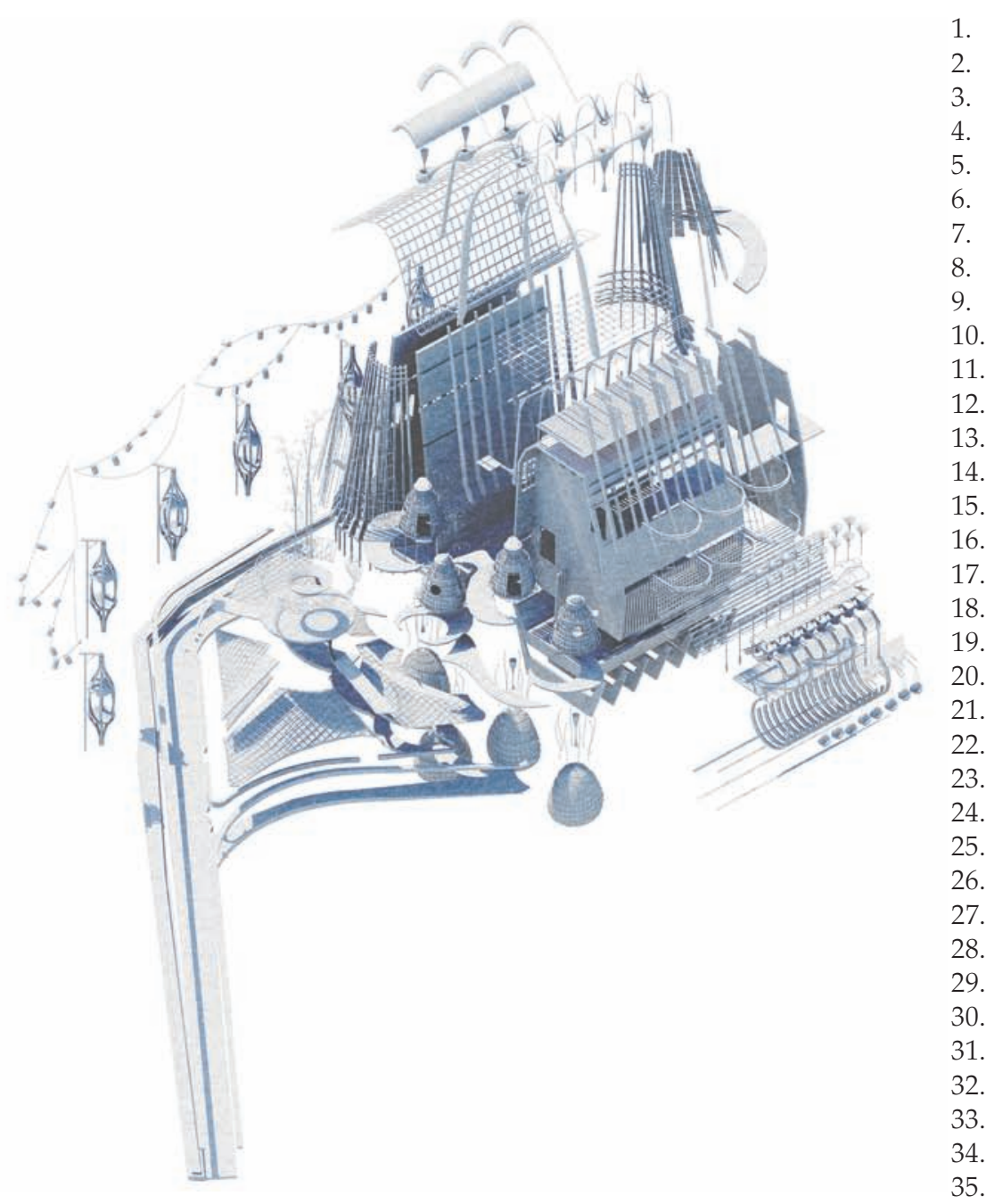

Figure 18: Axonometric view of the Chinese Kitchen in Ceramic Vessels in Time in Space Reassembling: 36. The Chinese Kitchen in Ceramic Vessels, ENIAtype, 2016. 


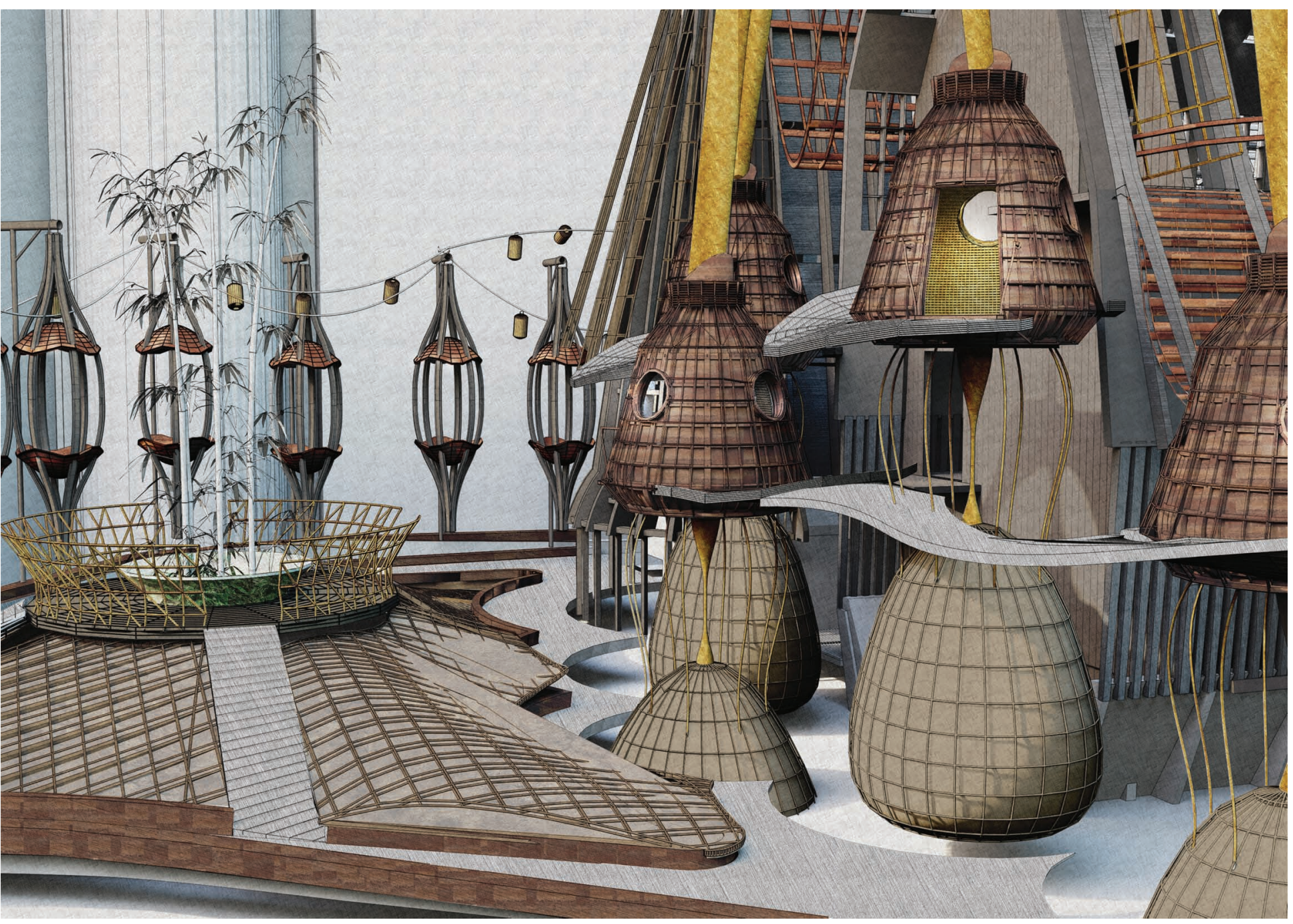

Figure 19: Perspective view of the Chinese tearooms in Time in Space Reassembling: The Chinese Kitchen in Ceramic Vessels, ENIAtype, 2016. 


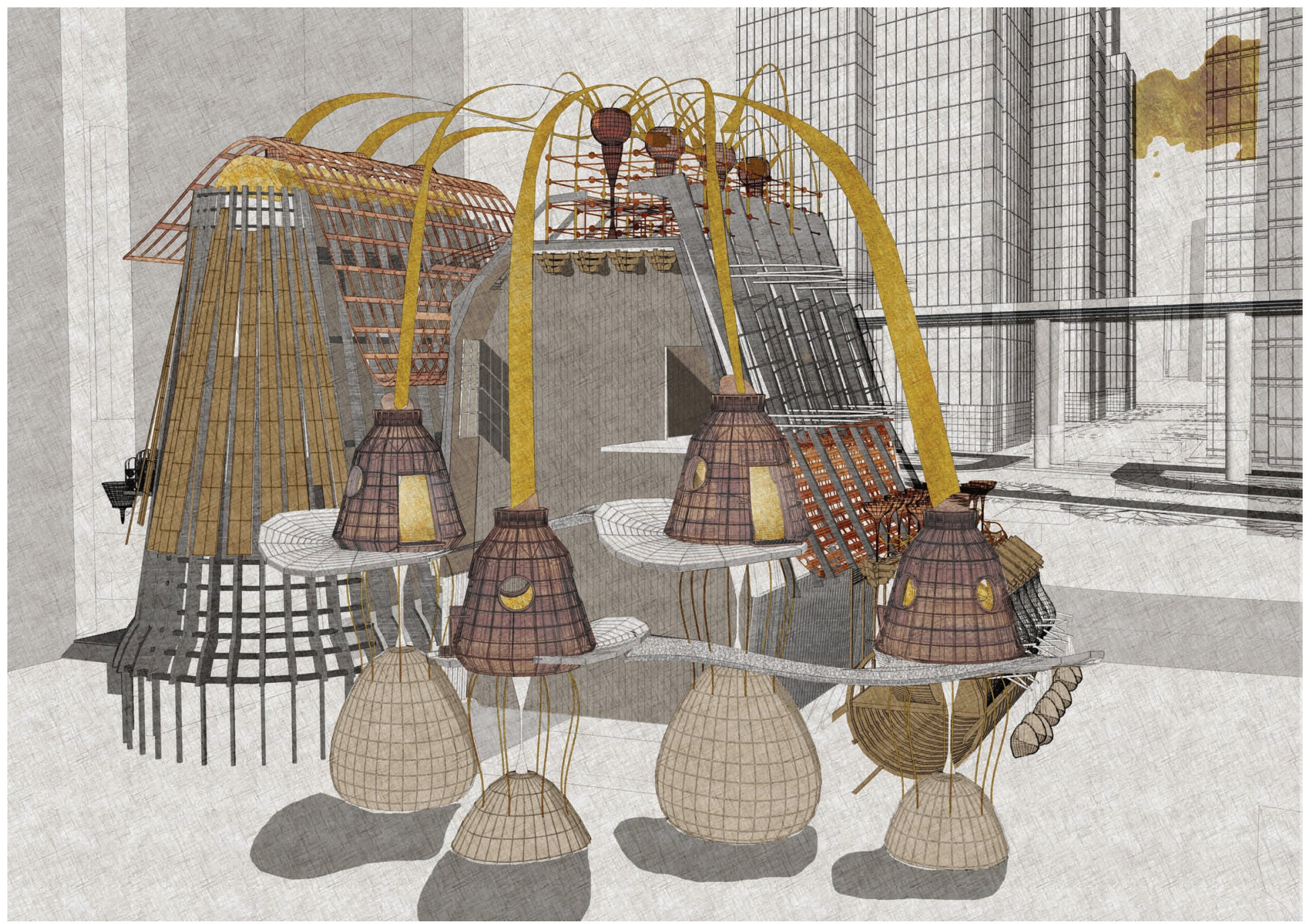



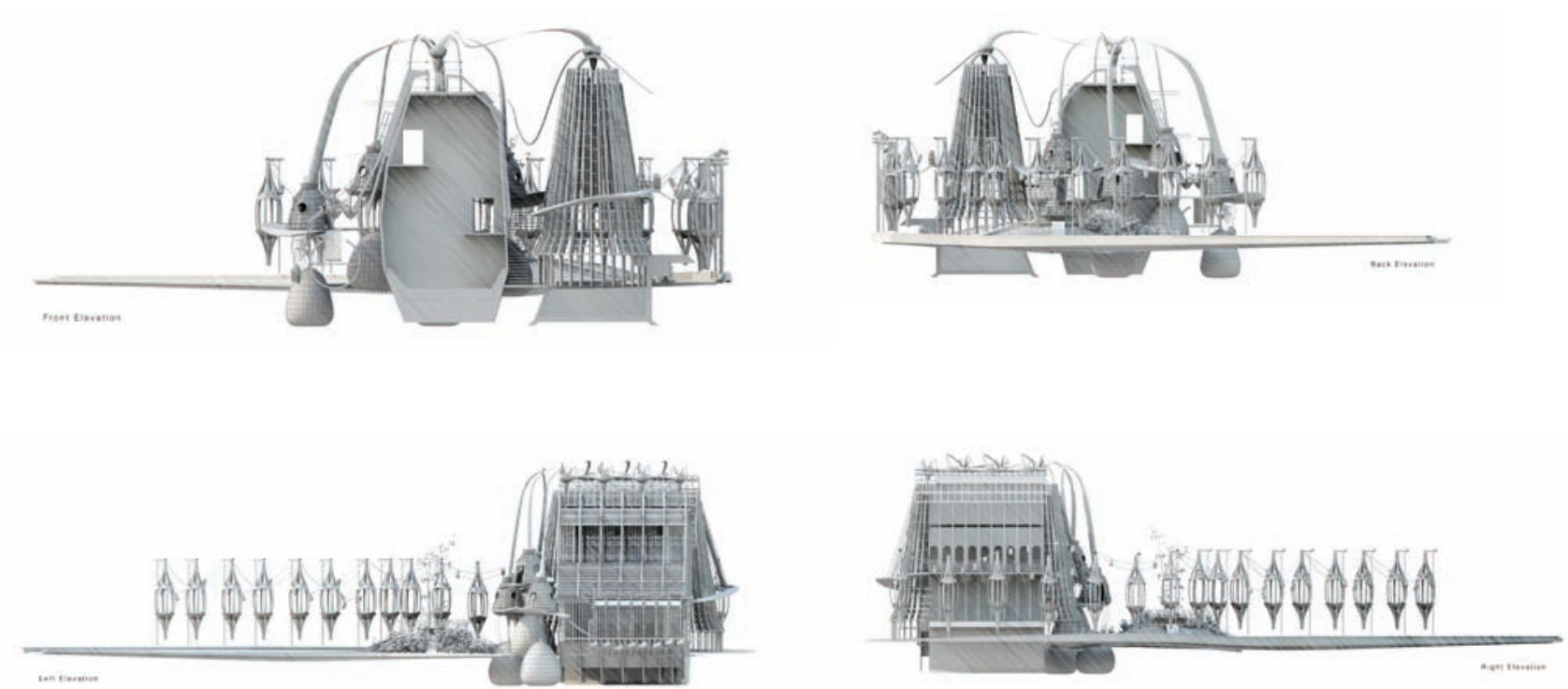

Figure 21: Sections through the Chinese Kitchen in Ceramic Vessels in Time in Space Reassembling: The Chinese Kitchen in Ceramic Vessels, ENIAtype, 2016.

21.

22.

23.

24.

25 .

26.

27.

28.

29.

30.

31.

32.

33.

34.

35.

36. 


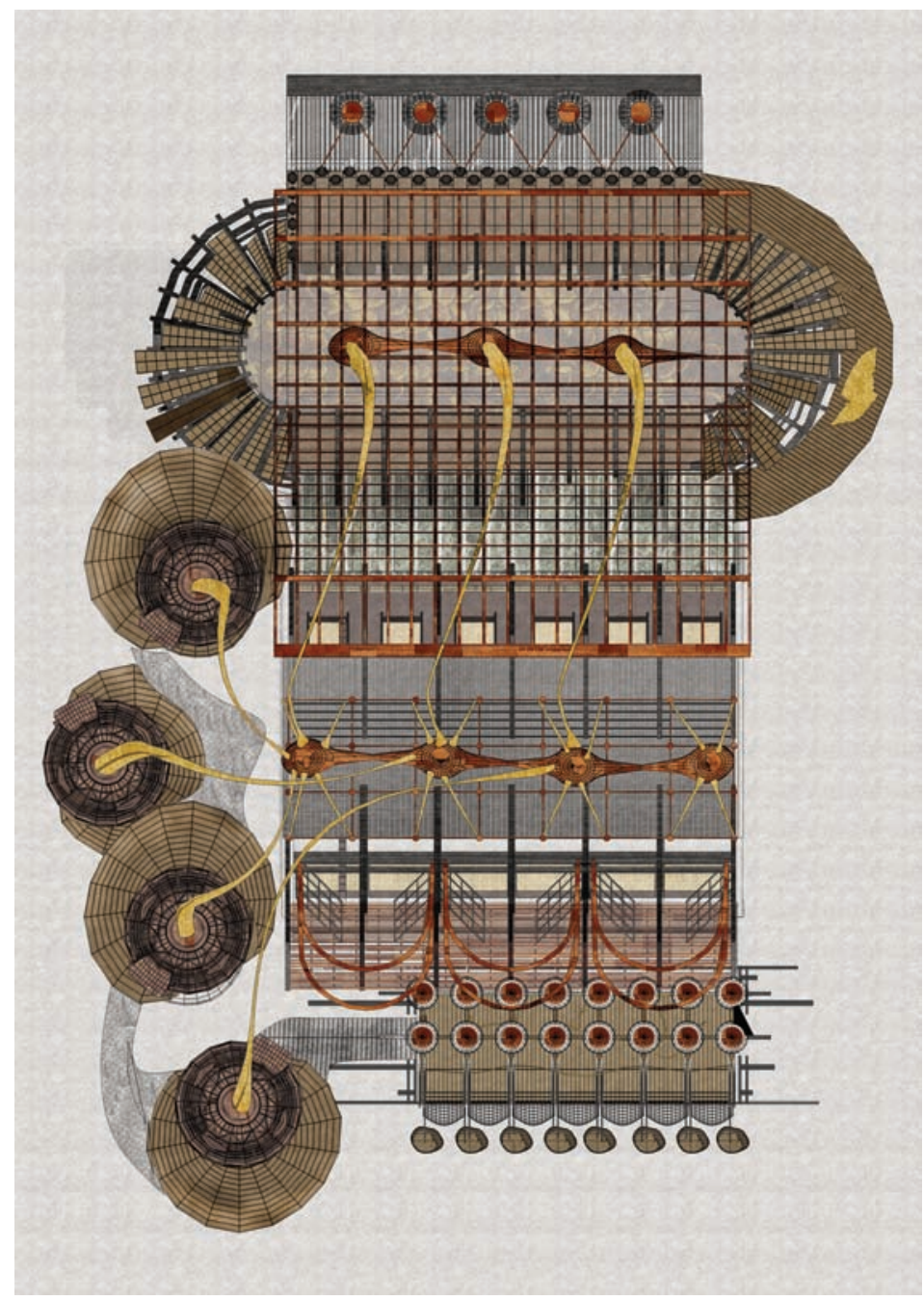

Figure 22: Roof plan of the Chinese Kitchen in Ceramic Vessels in Time in Space Reassembling: The Chinese Kitchen in Ceramic Vessels, ENIAtype, 2016. 


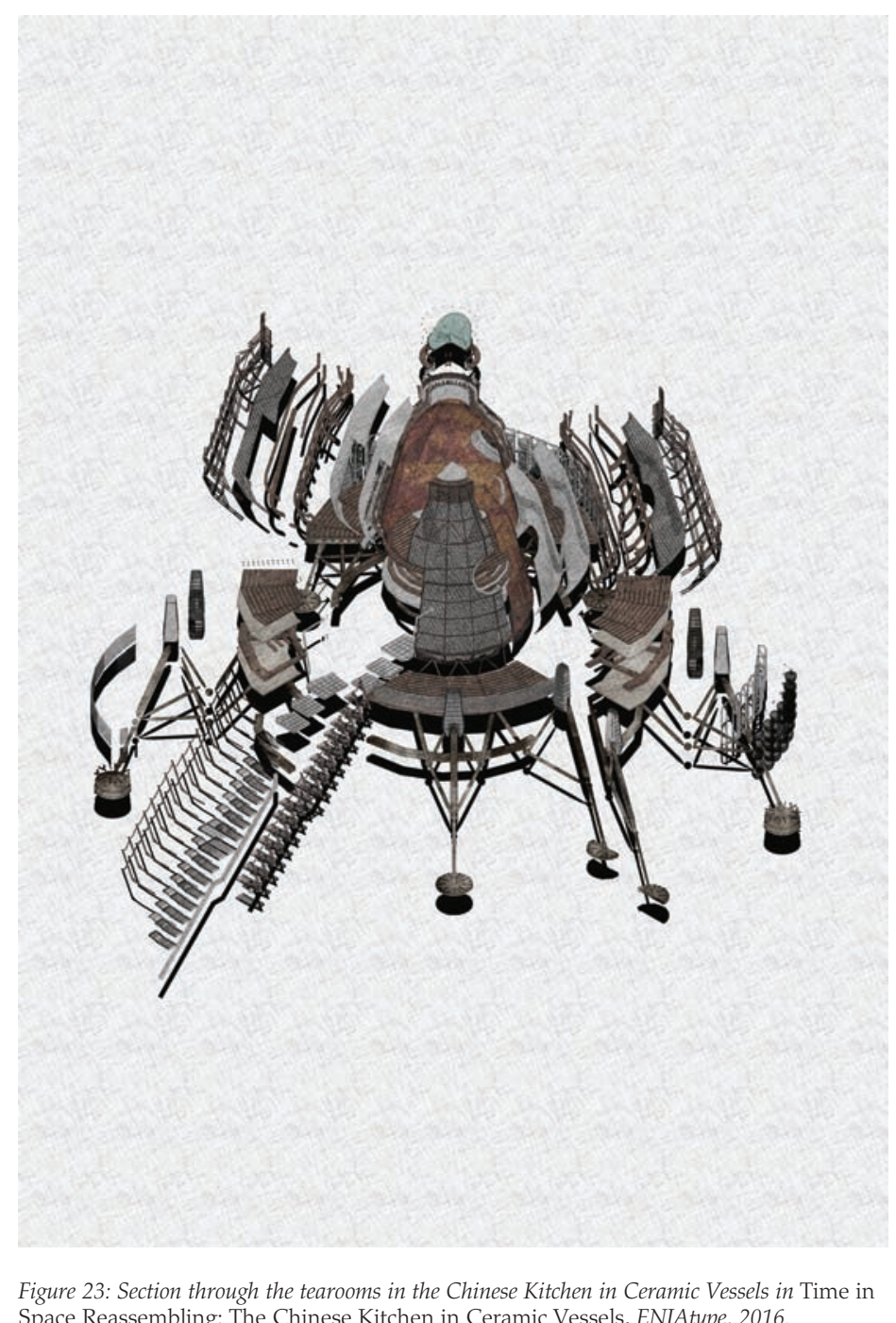

Space Reassembling: The Chinese Kitchen in Ceramic Vessels, ENIAtype, 2016. 

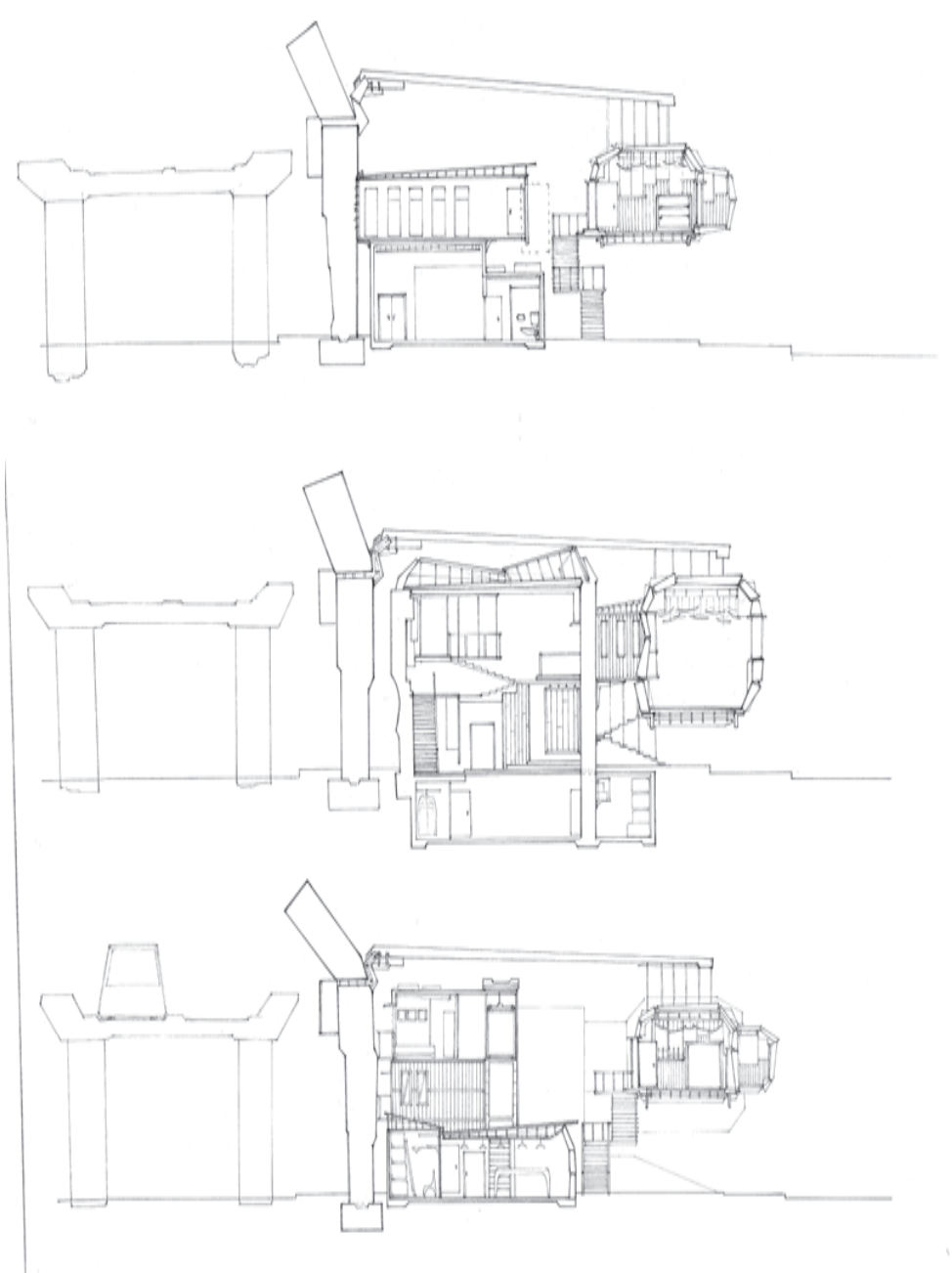
First Pages/Planman

Shaun Murray
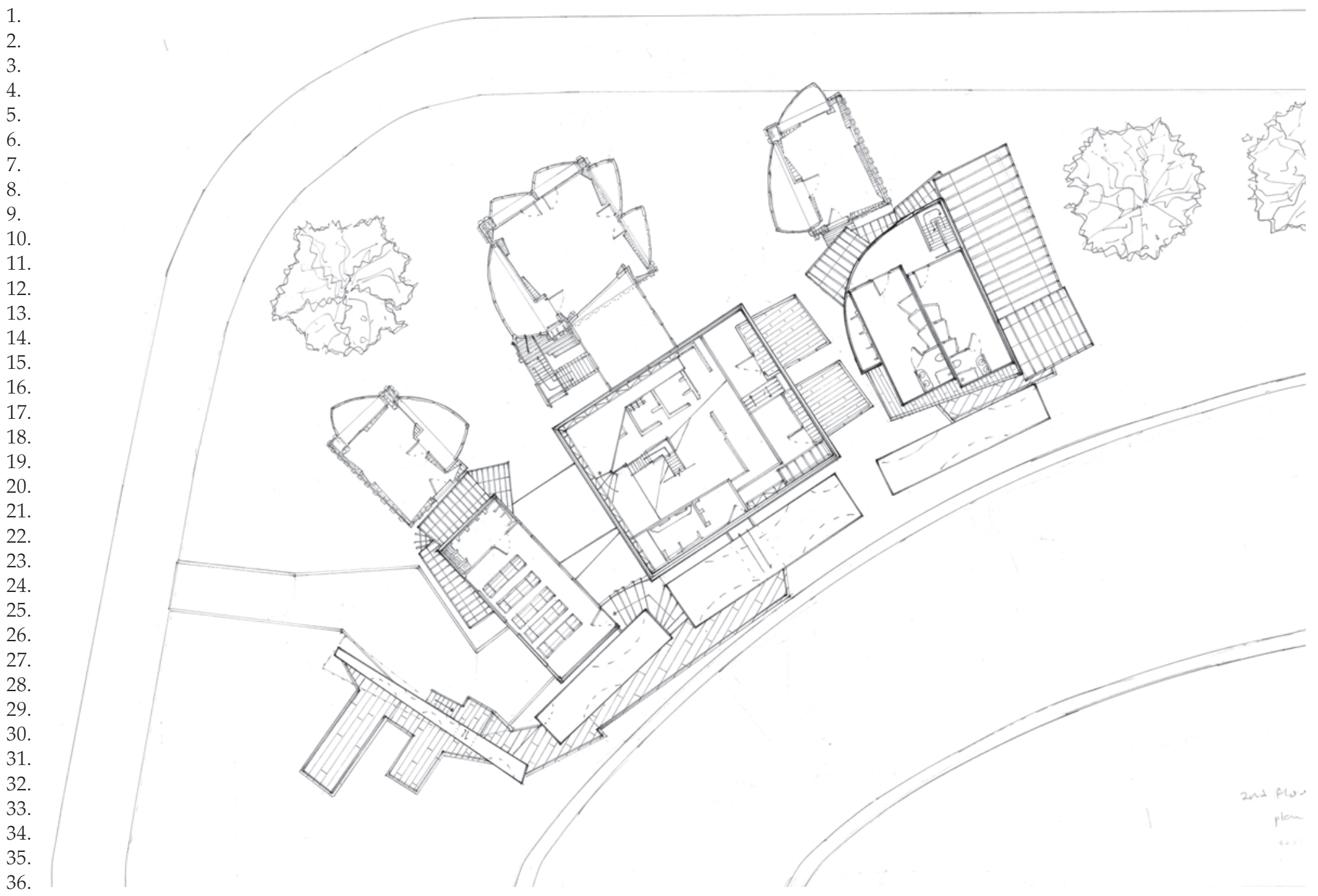

Figure 25: Plan of the recording studios in Resonations and Object Interference at the Recording Studios, ENIAtype, 2016.

Design Ecologies 
First Pages/Planman

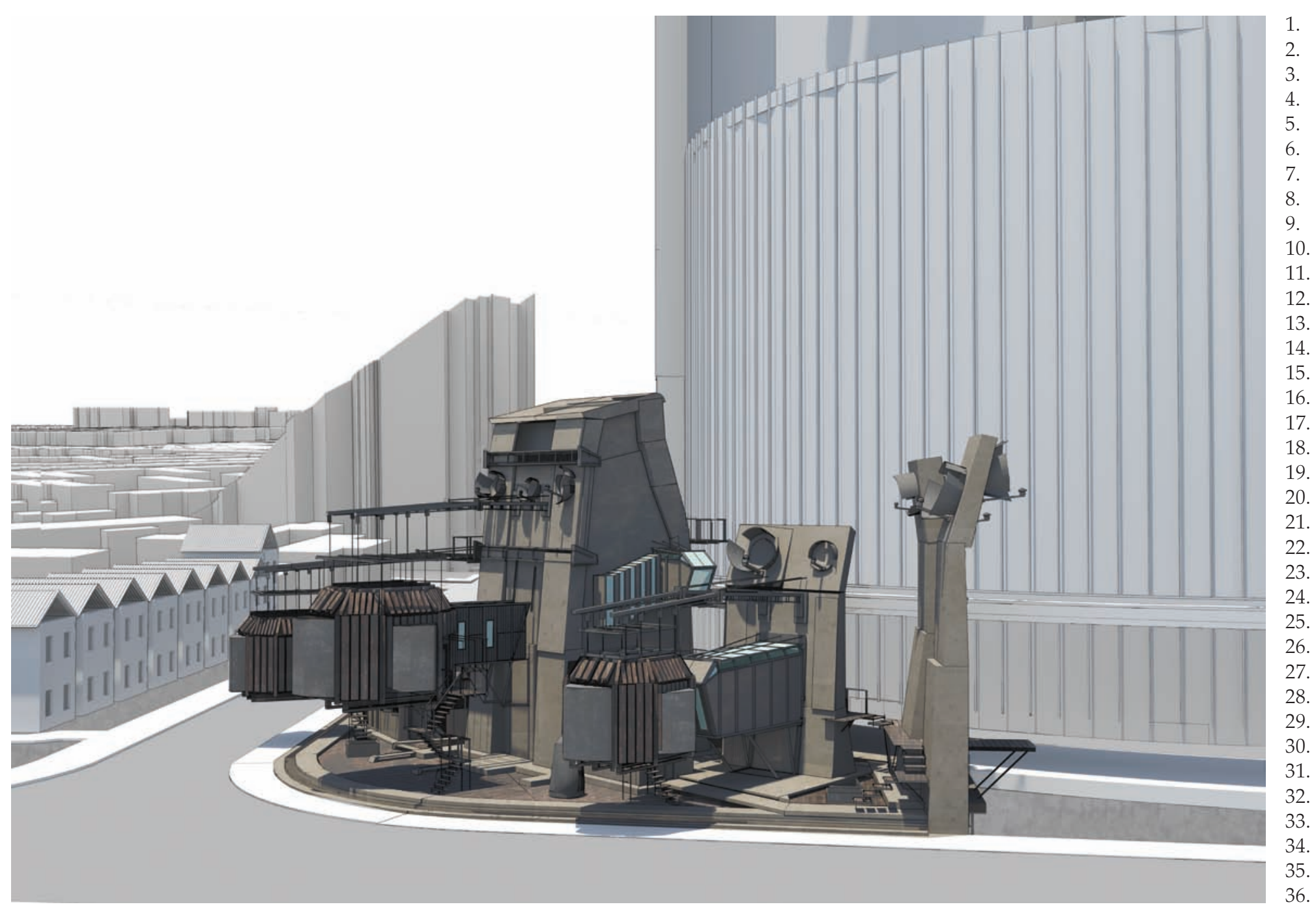

Figure 26: Perspective view of the recording studios in Resonations and Object Interference at the Recording Studios, ENIAtype, 2016. 

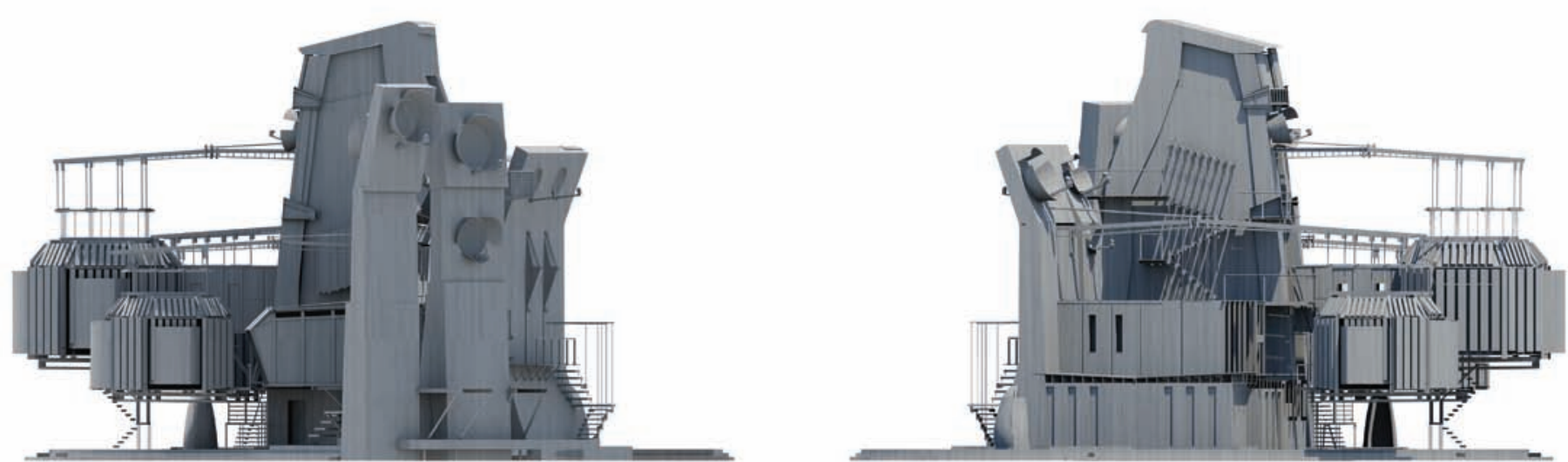

Figure 27: Elevations of the recording studios in Resonations and Object Interference at the Recording Studios, ENIAtype, 2016.

16.

7.

18.

19.

21.

22.

23.

24.

25.

26.

27.

28.

29.

30.

31.

32.

33.

34.

35.

36. 


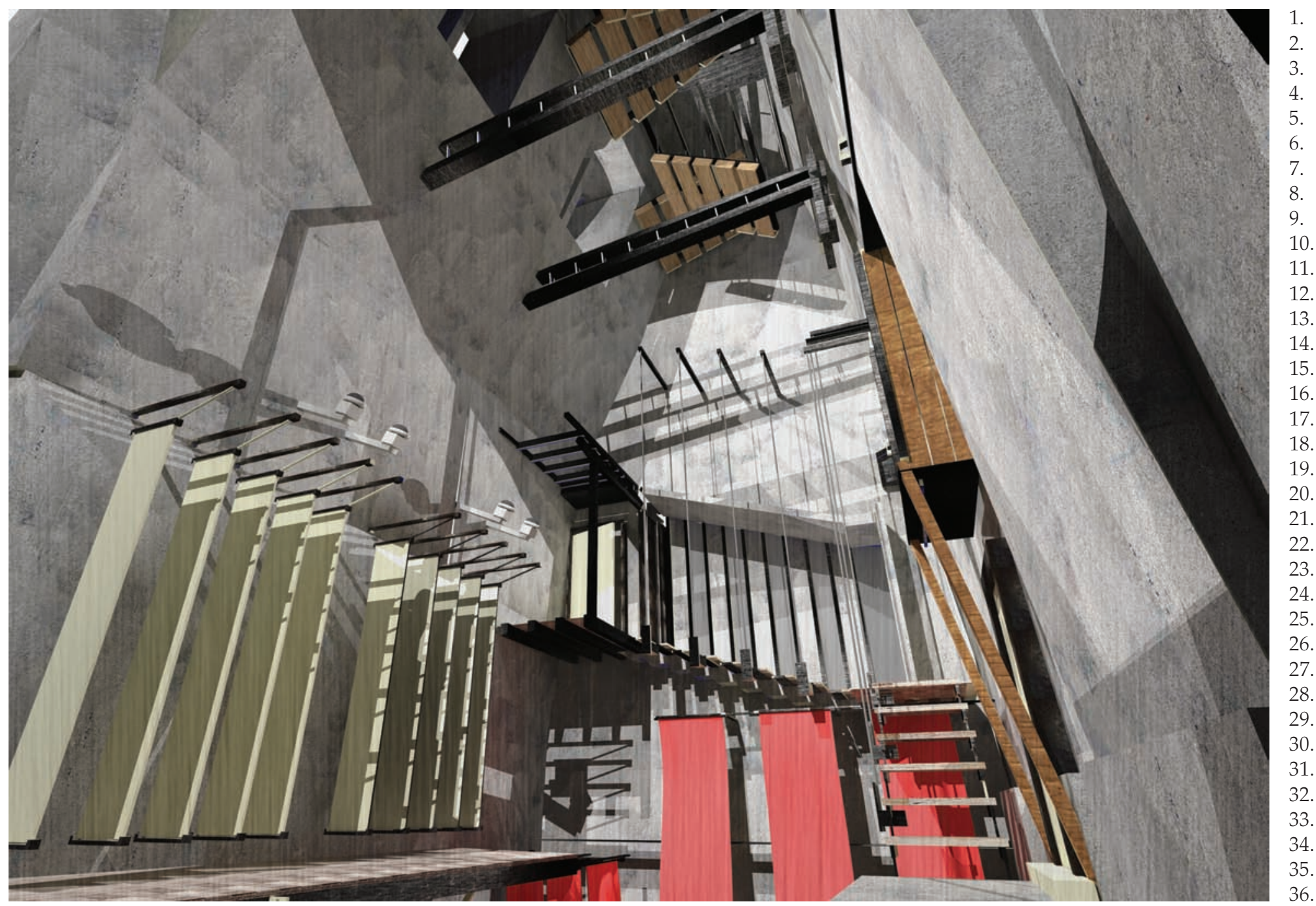

Figure 28: Interior view of the resonating chamber in Resonations and Object Interference at the Recording Studios, 2016 


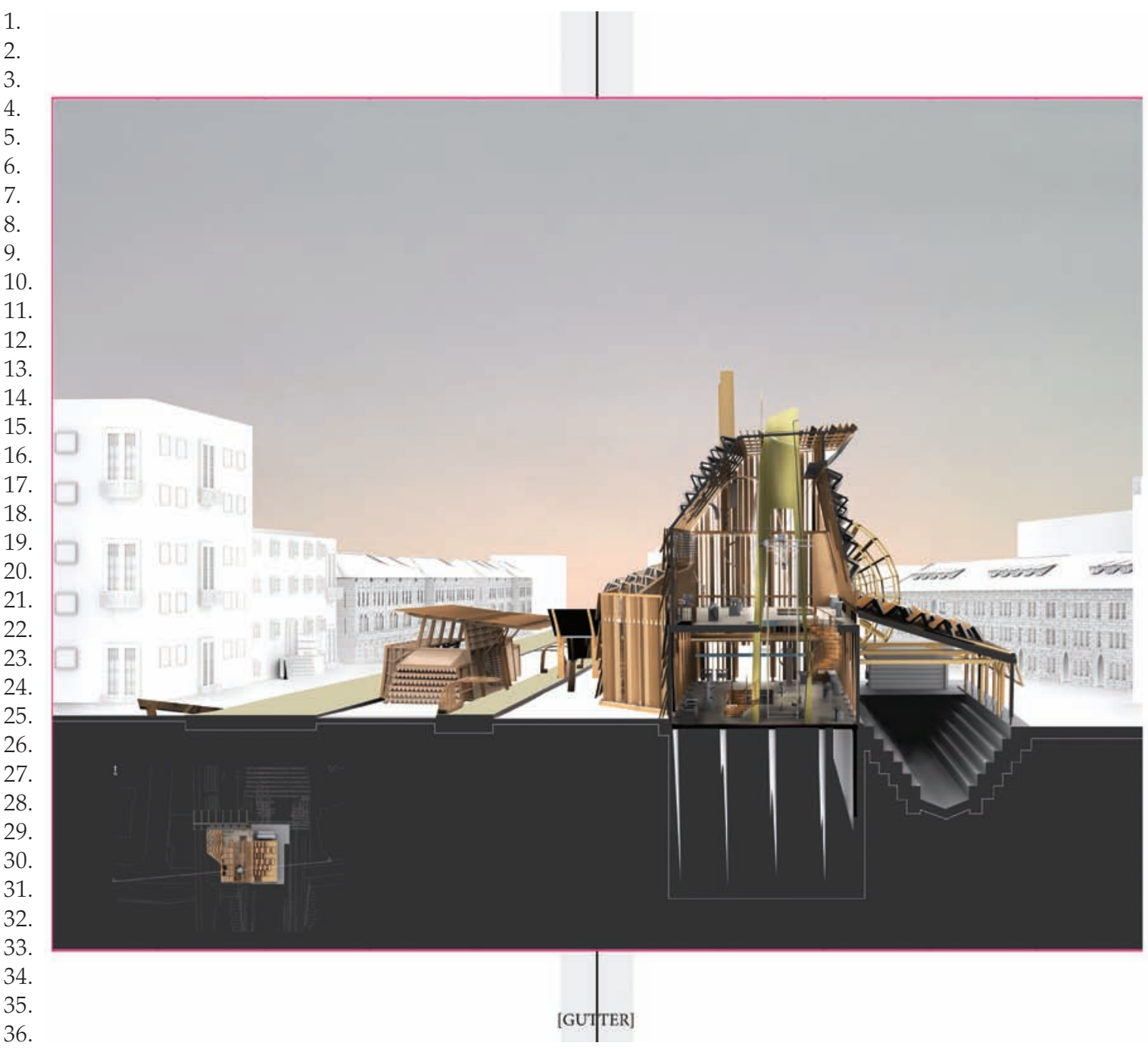

Figure 29: Section through wooden boat construction workshop in Brunel's Pier and the Timber Dockyard, 2016.

164 Design Ecologies 


\section{First Pages/Planman}

Architectural Forensics in Anonymous Monsters

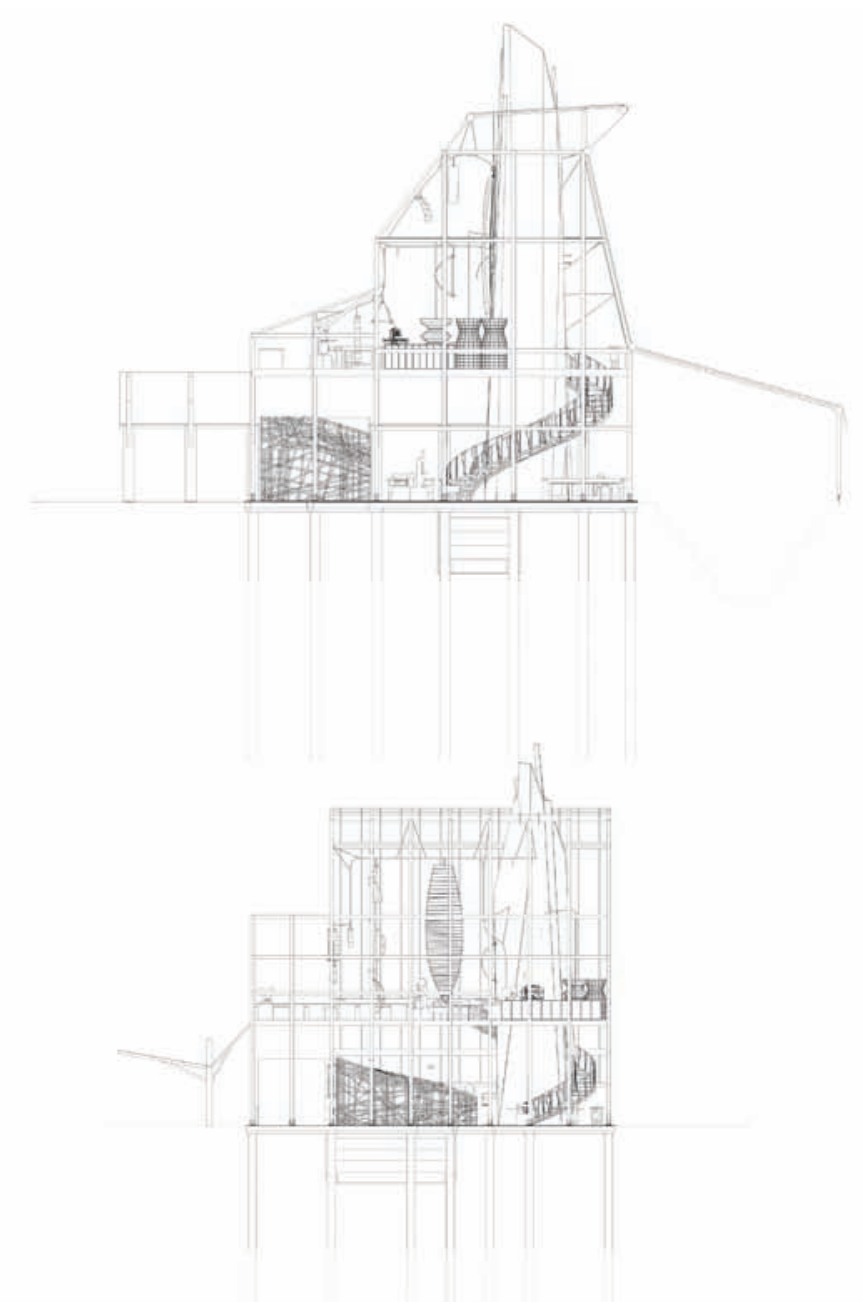

Figure 30: Sections through boat construction workshop in Brunel's Pier and the Timber Dockyard, 2016. 


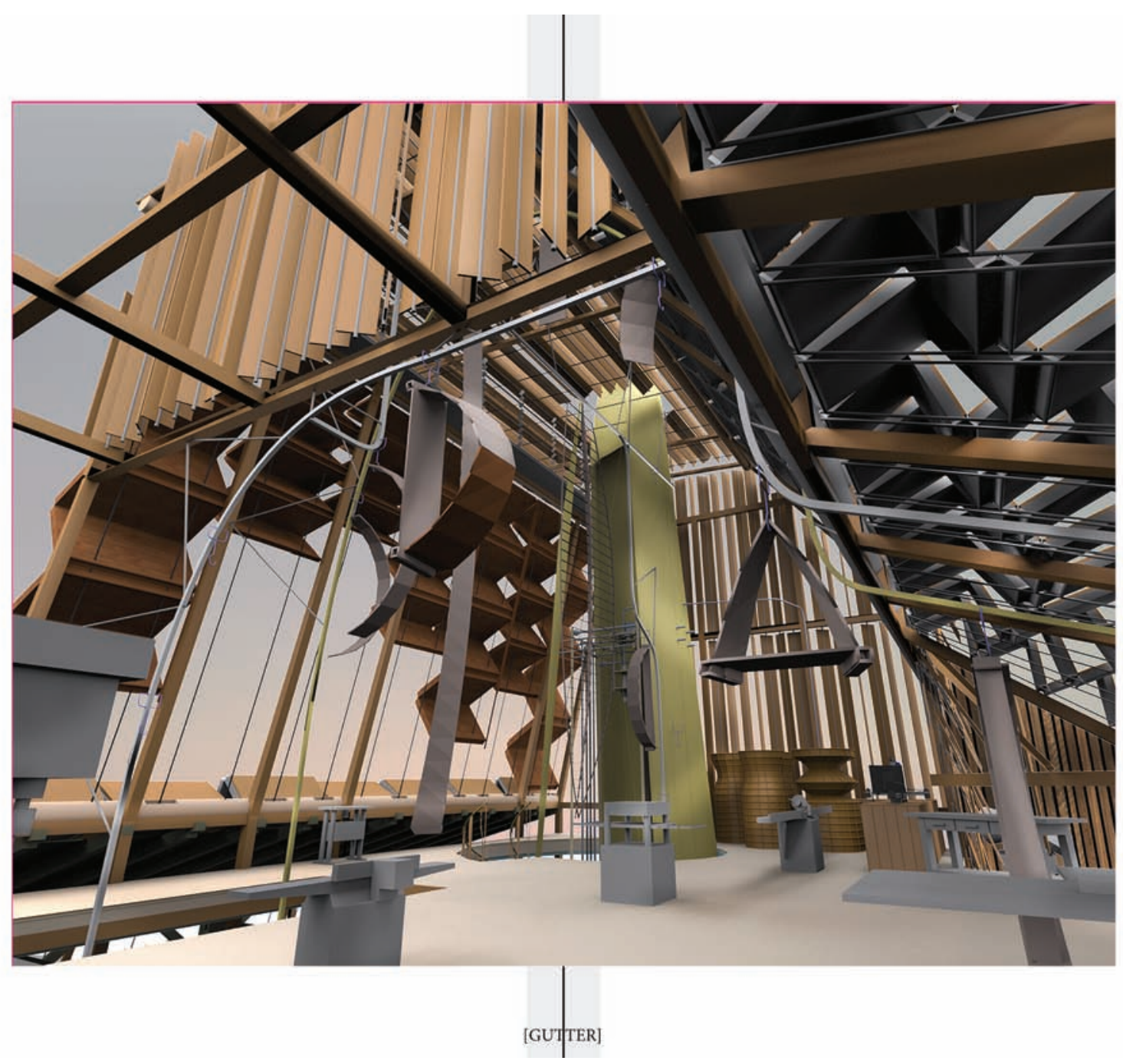

Figure 31: Interior of the main boat construction workshop in Brunel's Pier and the Timber Dockyard, 2016. 


\section{Conclusion}

For technologies to be useful in the design of architecture, we need to develop tactics to reveal something new. Technology is not a thing in itself, as it needs to be applied through a technique or techne. The objective of ENIAtype architecture is to design architecture through physical environmental data like Wi-Fi signals, light pollution, water Ph value, air speed and flow. We encourage the research group to question the architecture of cartographic technologies from Geographical Information Systems (GIS), Lidar scanning, aerial and geological surveys and complex transportation movements. The architecture is the outcome of the shifting relationships of our complex environment. All participants tailored the project brief to their own ideas of their own practice and everyone worked with a range of digital and analogue tools from 3D design, cartographic drawings and physical modelling. However, most of these third wave VR and augmented reality projects don't add anything meaningful to the field. Instead, they repeat the patterns of previous media and communication campaigns, such as museum guides and notice boards (now digital), and in some cases they even generate distraction and noise. These projects fail most notably when it comes to facing the debate about the materiality of objects and how to create immersive experiences. All of this happens at a time of such disruption that material and digital objects fuse together, a time when digital experimentation should help rethink the limits of analog materiality: its very presence, the notion of what is real and what is a copy, the body's involvement when engaging with an object, the role of archives, the concept of continuity within a gallery's exhibition, the relation between the visit and the after-visit in connection to the audience's virtual identities. The research group is trying to awake the energy contained in the environment. What is considered as empty space is just a manifestation of matter that is not awakened by the anonymous monster.

\section{Suggested citation}

Murray, S. (2015), 'Architectural Forensics in Anonymous Monsters', Design Ecologies, 5: 1, pp. 130-168, doi: 10.1386/des.5.1.130_1

\section{Contributor details}




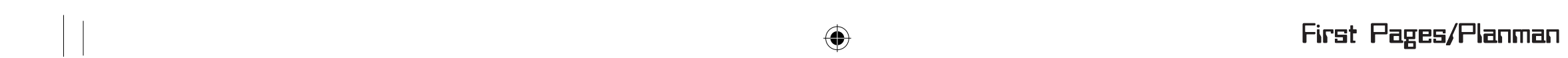

1. Architecture through the Centre for Advanced Inquiry in Integrative Arts (CAiiA) -Planetary

2. Collegium, University of Plymouth in 2011. He is actively involved in the future practice and educa-

3. tion of architecture around the world, including six years teaching Masters in Architecture at University

4. College London (UCL)- Bartlett School of Architecture, four years teaching design and technology

5. (iDAT) at University of Plymouth, three years teaching reflexive architecture at (AHO), The Oslo

6. School of Architecture and Design with lectures, symposiums and exhibitions at Architectural

7. Association (AA), Royal College of Art (RCA), Vienna University of Technology, Royal Melbourne

8. Institute of Technology (RMIT), Victoria University in New Zealand, Mok Won University in Seoul,

9. Sung-sil University in Seoul and (CAFA) in Beijing. Shaun has written extensively about an ecological

10. and environmental architecture in many international journals and highlighted by his book, Disturbing

11. Territories (Springer Wein: 2006), which documents the complexities of unpacking the environment

12. through architectural design.

13.

14. Contact: 10 Sunbury Lane, London SW11 3NP.

15. E-mail: shaun@eniatype.com

16.

17. Shaun Murray has asserted his right under the Copyright, Designs and Patents Act, 1988, to be 18. identified as the author of this work in the format that was submitted to Intellect Ltd. 